\title{
Strategies for synthesis of epoxy resins from oleic acid derived from food wastes.
}

Theodore Hayes, Yingxue Hu, Sandra A. Sanchez-Vazquez, Helen C. Hailes, Abil E. Aliev, Julian R. G. Evans

Department of Chemistry, University College London, 20 Gordon Street,

London.

WC1H 0AJ

UK

\section{Abstract}

The use of biomass-sourced chemical feedstocks creates a conflict over land use between food and fuel/chemical production. Such conflict could be reduced by making use of the annual $1.3 \mathrm{Pg}$ food waste resource. Oleic acid is available from seed oils such as pumpkin, grape, avocado and mango. Its esterification with diols 1,3-propanediol, resorcinol and orcinol was used to form diesters and the naturally occurring norspermidine was used to prepare a diamide, all under ambient conditions. These compounds were then epoxidised and polymerised. When esterification was followed by epoxidation and subsequent curing at elevated temperature with $p$-phenylenediamine or diethylenetriamine, hard insoluble resins were formed. When the sequence was changed such that the epoxidized oleic acid was first reacted with cis-1,2-cyclohexanedicarboxylic anhydride and then esterified with orcinol and resorcinol, insoluble crosslinked polymers were also obtained.

A study of the interaction between the precursors and their respective epoxides with untreated montmorillonite and five organically modified clays was made with the purpose of exploring the scope for nano-composite polymer production. Neither oleic acid nor epoxystearic acid demonstrated significant intercalation in unmodified montmorillonite clay even after 7.8 Ms. However, a quaternary ammonium pretreated clay, Cloisite 10A was swollen by oleic acid. This provides a potential route to generate in-situ polymerized nanocomposites in which both matrix and reinforcement have low embodied fossil carbon.

Keywords: oleic acid, biomass, epoxy resins, esterification, nanocomposites 
Introduction Petroleum is the main feedstock for monomer and polymer production and nearly $7 \%$ of world oil and gas is used for their manufacture ${ }^{1}$. More challenging extraction methods are likely to increase the background petroleum price in the long term so that biomass becomes increasingly viable as a chemical feedstock ${ }^{2-4}$. The literature on biomass-derived polymers has been dormant while petrochemicals dominated the market but is now expanding to reflect interest in 'sustainable' technologies ${ }^{5-7}$ and plant oils are a focus for this attention ${ }^{8,9}$. The conversion of landuse in poorer communities from food to biofuel production has caused conflict which would recur, mutatis mutandi, for chemical feedstock production ${ }^{10,11}$. It has thus been argued ${ }^{12}$ that the industrial fraction of the $1.3 \mathrm{Pg}$ per annum food waste resource can be exploited for materials production thus lessening land-use conflict. Food waste scales with population as does the demand for materials. Vegetable oils are triglyceride-based, generally liquids at room temperature with 94 96 wt.\% fatty acids $^{13}$ which can be differentiated by carbon chain length and the positions of double bonds, typically 14 22 carbon atoms and 0 to 3 alkenyl degrees of unsaturation ${ }^{14}$. The configuration and distribution of fatty acids influences the physical and chemical properties of materials produced from them ${ }^{15}$.

The objective here was to explore the synthesis of novel epoxy resins using a food waste, oleic acid, as the feedstock. World annual production of mango is $36 \mathrm{Tg}$ and mango seed oil contains $40 \%$ oleic acid, grape seed oil 15-20\%, pumpkin seed oil $32 \%$ and avocado seed oil $17 \%$, so industrial and agricultural food waste can be a significant source of oleic acid: consumer food waste is generally too contaminated to be a suitable resource.

Unsaturated fatty acids are obtained by treating triglycerides with sodium hydroxide followed by separation. They have at least one alkene functional group which may be epoxidized. These can undergo polymerisation reactions based on a succession of intermolecular cross-linkages via epoxide ring openings. As the extent of cross-linking increases, the resin becomes progressively more solid and less soluble ${ }^{16}$.

Epoxy resins can be cured by nucleophile initiated direct reaction between two resin molecules (homopolymerisation) ${ }^{17}$ and ring opening by photoinitiators (cationic photopolymerisation $)^{18}$ but the most common and important methods are those which use a curing agent or hardener (copolymerisation). These can be polyfunctional amines, cyclic anhydrides or polyphenols ${ }^{19}$. The many types of epoxy resins, curing processes and additives (such as plasticizers and reactive diluents) give rise to materials with a wide range of properties in applications such as paints, adhesives and composites ${ }^{16,20}$.

Natural unsaturated fatty acids tend to occur as cis-isomers. Oil is extracted from seed waste by pressing and oleic acid can be isolated by low temperature crystallisation. Epoxidation of oleoyl unsaturations can be achieved by the action of peroxides or peracids. Two common reagents used 
for this purpose are meta-chloroperbenzoic acid $(m \mathrm{CPBA})^{21}$ and hydrogen peroxide $\left(\mathrm{H}_{2} \mathrm{O}_{2}\right)^{15}$. Previous investigations have found that epoxidation using $\mathrm{H}_{2} \mathrm{O}_{2}$ works best in the presence of an organic acid such as acetic or formic acid, which forms a peracid with the peroxide ${ }^{15,22}$. The carboxylic group in oleic acid could potentially be used to replace added carboxylic acids for in-situ peracid generation as, according to Fong, et al. ${ }^{23}$, peracid could be generated when the ester group and hydrogen peroxide are combined. However, this reaction can only happen either at $\mathrm{pH}$ around 10 or in the presence of catalyst ${ }^{23,24}$.

Epoxy resins with two epoxide groups per molecule can be cured using polyamines without needing a catalyst or solvent ${ }^{19,22}$. Possible polyamine hardeners include triethylenetetramine (TETA) and $p$-phenylenediamine (PPD). Diepoxides that may be appropriate for this procedure are epoxidized dioleates (diesters of oleic acid) or dioleamides (diamides of oleic acid). Dioleates may be prepared at room temperature via a Steglich esterification between oleic acid and a diol such as orcinol or resorcinol, by using 4-(dimethylamino)pyridine (DMAP) and $N, N^{\prime}-$ dicyclohexylcarbodiimide $(\mathrm{DCC})^{25}$. Reaction of the extract from aloes ${ }^{26}$ or the plant resin asafoetida ${ }^{27}$ with potassium hydroxide can be used to produce orcinol or resorcinol respectively. Dioleamides may be prepared at room temperature by reaction of oleoyl chloride with a polyamine ${ }^{28-30}$.

Norspermidine possesses two primary amines and one sterically hindered secondary amine group. It can therefore be used to prepare a dioleamide. Although toxic, norspermidine occurs naturally in a number of plants, algae and bacteria such as Lucerne ${ }^{31}$, red algae ${ }^{32}$ and $V$. parahaemolyticus ${ }^{33}$.

One of the most straightforward methods to produce oleic acid-based polymers is via homopolymerisation: epoxidation of the acid followed by cross-linking directly between the epoxide groups. Previous investigations have shown that these processes often demand high curing temperatures of $100-200{ }^{\circ} \mathrm{C}$ applied for periods of 1-4 hours for effective cross-linking to be achieved, but that a solvent is not usually needed ${ }^{34}$. Homopolymerisation also requires a Lewis base initiator to proceed such as piperidine, $p$-phenylenediamine (PPD) or triethylamine $\left(\mathrm{NEt}_{3}\right)^{17,34}$. One promising route to thermosetting materials from biomass is the crosslinking of epoxidized sucrose esters of fatty acids ${ }^{35}$ for uses in coatings, adhesive and composites and tensile strengths of $18 \mathrm{MPa}$ have been obtained ${ }^{36}$

The two main classes of crosslinking agents applied to epoxides for polymerization are amines and anhydrides. Such reactions have been widely studied ${ }^{37,38}$. The amine curing process takes place at the stoichiometric ratio ${ }^{37}$ and room temperature as amines exhibit high nucleophilicity. Anhydride curing has been studied for the last 50 years ${ }^{39}$. Usually an initiator is used as the epoxy/anhydride does not react directly and therefore an active hydrogen must open the 
ring of the anhydride curing agent first ${ }^{40,41}$. In this case, a tertiary amine was used as initiator (triethylamine).

The use of biomass for preparing structural resins is not new. In the interwar years, Henry Ford invested heavily in the use of soybean oil in vehicle manufacture ${ }^{42}$. The use of smectite clays for reinforcing polyamides also originated in the motor industry in $1985^{43}$ and such polymer-clay nancomposites have expanded ${ }^{44}$ to provide materials with superior elastic modulus, strength, heat distortion and barrier properties. Three types of composite are seen: (a) a conventional composite in which the polymer does not enter the galleries, (b) an intercalated nanocomposite in which the polymer distributes itself throughout the galleries but the clay layers remain stacked and (c) an exfoliated nanocomposite in which clay layers are dispersed and separated. The last is preferred as it provides superior properties but actually most nanocomposites contain both exfoliated and intercalated fractions. Such nanocomposites can be made by melt intercalation, solution intercalation and in-situ intercalative polymerization in which the unreacted polymer precursors are hosted by the galleries before reacting. Such composites, prepared from food waste derived polymers offer the prospect of a composite material with extremely low embodied fossil carbon.

In this work, two approaches to form oleic acid-based polymers have been used. First, oleic acid was coupled to diols and a diamine to give two alkenyl groups per molecule then epoxidized and polymerized. In an alternative approach oleic acid was first epoxidized then reacted with anhydride to crosslink and then esterified.

\section{EXPERIMENTAL}

\section{Materials and Measurements}

The major component of mango butter is oleic acid (40-46\%) which can be separated from other components (mainly stearic at $40-45 \%$ with palmitic, linoleic and arachidic together $\sim 10 \%$ ) by crystallization of saturated acids from aqueous acetone solution at $-25{ }^{\circ} \mathrm{C}^{45,46}$ to give the oleic acid at $>90 \%$ purity. In this work, commercially available oleic acid at 90\% (Sigma Aldrich Chemical Co, Gillingham, UK) was used in the synthesis of monomers. It is envisaged that impurities will be comparable to those in technical grade oleic acid and will not influence the epoxidation reaction.

Orcinol, resorcinol, oleic acid (90\%), 4-(dimethylamino) pyridine, $N, N^{\prime}-$ dicyclohexylcarbodiimide, hexane, ethyl acetate, norspermidine, pyridine, benzene, oleoyl chloride, acetone, meta-chloroperbenzoic acid, diethylenetriamine, titanium (IV) $n$-butoxide (99\%) and $p$-phenylenediamine were purchased from Sigma Aldrich Chemical Co, Gillingham, UK. Triethylamine, Geduran ${ }^{\circledR}$ silica gel 60 and 30\% hydrogen peroxide were from Merck KGaA, Darmstadt Germany. Formic acid (98\%) was from VWR Lutterworth UK. Toluene and dichloromethane were purchased from Fisher Scientific, Loughborough UK. 1,3-Propanediol and 
cis-1,2-cyclohexanedicarboxylic anhydride were purchased from Alfa Aesar. Deuterated chloroform $\mathrm{CDCl}_{3}(99.8 \%)$ was purchased from Apollo scientific, Heysham UK. The montmorillonites used were Nanofil 116 ${ }^{\circledR}$ and Cloisite ${ }^{\circledR}$ 10A (Rockwood Company, Southern Clay Products Inc. Texas USA) and in some cases were modified as described below. Other reagents were used as supplied without modification or purification.

IR spectra were taken on a Bruker-FTIR-ALPHA Platinum ATR with a single reflection diamond ATR module with a scan rate of 16 and a wavelength range from 4000 to $600 \mathrm{~cm}^{-1}$. A Siemens D500 diffractometer with $\mathrm{Cu} \mathrm{K} \alpha_{1}$ radiation $(\lambda=1.54056 \AA)$ was used for X-ray diffraction measurements with a scanning step of $0.05^{\circ}$ and a scan time of 4 seconds per step. Mass spectra were recorded on a Waters Acquity uPLC SQD using HPLC grade water and acetonitrile (both with $0.1 \%$ formic acid) as the solvents. Solution NMR spectra were recorded on Bruker spectrometers AMX300, Avance 500 and Avance III 600, with ${ }^{1} \mathrm{H}$ NMR Larmor frequencies of 300, 500 and 600 $\mathrm{MHz}$, respectively. Chemical shifts (in ppm) relative to tetramethylsilane (TMS) were calibrated using the residual solvent peak $\left({ }^{1} \mathrm{H} 7.26 \mathrm{ppm}\right.$ in $\left.\mathrm{CDCl}_{3}\right)$. Coupling constants $(J)$ were measured in Hertz $(\mathrm{Hz})$ and multiplicities for ${ }^{1} \mathrm{H}$ NMR coupling are expressed as $\mathrm{s}$ (singlet), $\mathrm{d}$ (doublet), $\mathrm{t}$ (triplet), quint (quintet), and m (multiplet). A Bruker Avance 300 NMR spectrometer with a $7.05 \mathrm{~T}$ wide-bore magnet and a $4 \mathrm{~mm}$ magic-angle spinning (MAS) probe was used to record solid-state NMR spectra. High-resolution solid-state ${ }^{13} \mathrm{C}$ NMR spectra at $75.5 \mathrm{MHz}$ were recorded at ambient probe temperature using cross-polarization $(\mathrm{CP})$, MAS $(8 \mathrm{kHz})$, high-power proton decoupling (HPPD) and total suppression of spinning sidebands (TOSS). Typical acquisition conditions were: ${ }^{1} \mathrm{H} 90^{\circ}$ pulse duration $2.45 \mu \mathrm{s}$; contact time $2 \mathrm{~ms}$; recycle delay $5 \mathrm{~s} .{ }^{13} \mathrm{C}$ CPMAS TOSS spectra with non-quaternary suppression (NQS) were also acquired with a $50 \mu$ s dephasing delay to suppress signals from motionally rigid $\mathrm{CH}$ and $\mathrm{CH}_{2}$ carbons. For direct detection of ${ }^{13} \mathrm{C}$ nuclei with $\mathrm{HPPD}$, the ARINGDEC pulse sequence was used with suppression of probe ringdown effects, which also suppresses the background signal. Typical acquisition conditions were: ${ }^{13} \mathrm{C} 90^{\circ}$ pulse duration $=3.0$ $\mu \mathrm{s}$; recycle delay $=15 \mathrm{~s}$. The solid-state ${ }^{13} \mathrm{C}$ NMR chemical shifts are expressed relative to TMS by using the resonance line at $176.46 \mathrm{ppm}$ for the $\alpha$ polymorph of glycine as an external standard.

\section{Monomer synthesis and purification.}

Diesters To oleic acid (2.2 equiv.), diols 1,3-propanediol (1.0 equiv.), orcinol (1.0 equiv.) or resorcinol (1.0 equiv.) in dichloromethane $\left(\mathrm{CH}_{2} \mathrm{Cl}_{2}\right)$ at $0{ }^{\circ} \mathrm{C}$ was added 4-(dimethylamino)pyridine (DMAP) (0.03 equiv.) and then $N, N^{\prime}$-dicyclohexylcarbodiimide (DCC) (2.4 equiv.). The reaction was stirred for $24 \mathrm{~h}$ at room temperature, the solid formed was removed by filtration and the solvent 
removed in vacuo. Either crude material was directly carried through to the next epoxidation step or was purified by column chromatography as detailed below.

Oleoate propyl diester diol ${ }^{47}$ The reaction was carried out using oleic acid (69 g, $0.22 \mathrm{~mol}$; 90\% purity), 1,3-propanediol (7.6 g, $0.10 \mathrm{~mol}$ ), DMAP (3.6 g, $0.03 \mathrm{~mol}$ ) and DCC (49.4 g, 0.24 mmol) in $\mathrm{CH}_{2} \mathrm{Cl}_{2}(200 \mathrm{~mL})$. The urea precipitate formed was removed by filtration and product isolated from the filtrate (32 g, 53\%). NMR spectroscopic analysis indicated that the product was isolated in $>90 \%$ purity so it was taken directly through to the next epoxidation step. ${ }^{1} \mathrm{H}$ NMR (300 $\left.\mathrm{MHz} \mathrm{CDCl}_{3}\right) \delta 5.29-5.35(4 \mathrm{H}, \mathrm{m}, 2 \times \mathrm{CH}=\mathrm{CH}), 4.14\left(4 \mathrm{H}, \mathrm{t}, J 6.0 \mathrm{~Hz}, 2 \times \mathrm{CH}_{2} \mathrm{OCO}\right), 2.29(4 \mathrm{H}, \mathrm{t}, J$ $\left.7.5 \mathrm{~Hz}, 2 \times \mathrm{CH}_{2} \mathrm{CO}\right), 1.93-2.03\left(10 \mathrm{H}, \mathrm{m}, 4 \times=\mathrm{CHCH}_{2}, \mathrm{CH}_{2} \mathrm{CH}_{2} \mathrm{O}\right), 1.58-1.63\left(4 \mathrm{H}, \mathrm{m}, 2 \times \mathrm{CH}_{2}\right)$, 1.19-1.34 (40H, m, $\left.20 \times \mathrm{CH}_{2}\right), 0.87\left(6 \mathrm{H}, \mathrm{t}, J 6.0 \mathrm{~Hz}, 2 \times \mathrm{CH}_{2} \mathrm{CH}_{3}\right)$.

Orcyl dioleate The reaction was carried out using oleic acid (17.28 g, $55.1 \mathrm{mmol} ; 90 \%$ purity), orcinol (3.10 g, $25.0 \mathrm{mmol})$, DMAP (0.092 g, $0.75 \mathrm{mmol})$ and DCC (12.4 g, $60.0 \mathrm{mmol})$ in $\mathrm{CH}_{2} \mathrm{Cl}_{2}(100 \mathrm{~mL})$. The product was purified by column chromatography (hexane/ethyl acetate $30: 1$ ) to give orcyl dioleate as a pale yellow oil $(7.59 \mathrm{~g}, 47 \%) .{ }^{1} \mathrm{H} \mathrm{NMR}\left(500 \mathrm{MHz} ; \mathrm{CDCl}_{3}\right) \delta 6.77(2 \mathrm{H}, \mathrm{s}$, $\mathrm{ArH}), 6.68(1 \mathrm{H}, \mathrm{s}, \mathrm{ArH}), 5.30-5.41(4 \mathrm{H}, \mathrm{m}, 2 \times \mathrm{CH}=\mathrm{CH}), 2.52\left(4 \mathrm{H}, \mathrm{t}, J 7.5 \mathrm{~Hz}, 2 \times \mathrm{CH}_{2} \mathrm{CO}\right), 2.35$ $\left(3 \mathrm{H}, \mathrm{s}, \mathrm{ArCH}_{3}\right), 1.91-2.09\left(8 \mathrm{H}, \mathrm{m}, 4 \times=\mathrm{CHCH}_{2}\right), 1.68-1.78\left(4 \mathrm{H}\right.$, quint, $\left.J 7.5 \mathrm{~Hz}, 2 \times \mathrm{CH}_{2} \mathrm{CH}_{2} \mathrm{CO}\right)$, 1.19-1.44 (40H, m, $\left.20 \times \mathrm{CH}_{2}\right), 0.84-0.93\left(6 \mathrm{H}, \mathrm{t}, J 7.0 \mathrm{~Hz}, 2 \times \mathrm{CH}_{2} \mathrm{CH}_{3}\right) ; m / z(\mathrm{CI}+) 653\left(\mathrm{M}^{+}, 67 \%\right)$, $265\left(\mathrm{CH}_{3}\left(\mathrm{CH}_{2}\right)_{7} \mathrm{HC}=\mathrm{CH}\left(\mathrm{CH}_{2}\right)_{7} \mathrm{CO}^{+}, 100 \%\right)$.

Resorcyl dioleate The reaction was carried out using oleic acid (17.3 g, $55.1 \mathrm{mmol} ; 90 \%$ purity), resorcinol (2.77 g, $25.2 \mathrm{mmol})$, DMAP (0.092 g, $0.75 \mathrm{mmol})$ and DCC (12.4 g, $60.0 \mathrm{mmol})$ in $\mathrm{CH}_{2} \mathrm{Cl}_{2}(100 \mathrm{~mL})$. The product was purified by column chromatography (hexane/ethyl acetate $30: 1)$ to give resorcyl dioleate as a pale yellow oil $(13.2 \mathrm{~g}, 82 \%) .{ }^{1} \mathrm{H}$ NMR $\left(500 \mathrm{MHz} ; \mathrm{CDCl}_{3}\right) \delta$ $7.34(1 \mathrm{H}, \mathrm{t}, J 8.0 \mathrm{~Hz}, \mathrm{ArH}), 6.95(2 \mathrm{H}, \mathrm{d}, J 8.0 \mathrm{~Hz}, \mathrm{ArH}), 6.89(1 \mathrm{H}, \mathrm{s}, \mathrm{ArH}), 5.30-5.41$ (4H, m, $2 \times$ $\mathrm{C} H=\mathrm{CH}), 2.53\left(4 \mathrm{H}, \mathrm{t}, J 6.8 \mathrm{~Hz}, \mathrm{CH}_{2} \mathrm{CO}\right), 1.93-2.10\left(8 \mathrm{H}, \mathrm{m}, 4 \times=\mathrm{CHCH}_{2}\right), 1.73(4 \mathrm{H}$, quint, $J 6.8$ $\left.\mathrm{Hz}, 2 \times \mathrm{CH}_{2} \mathrm{CH}_{2} \mathrm{CO}\right), 1.19-1.46\left(40 \mathrm{H}, \mathrm{m}, 20 \times \mathrm{CH}_{2}\right), 0.87\left(6 \mathrm{H}, \mathrm{t}, J 7.0 \mathrm{~Hz}, 2 \times \mathrm{CH}_{2} \mathrm{CH}_{3}\right) ; m / z(\mathrm{CI}+)$ $639\left(\mathrm{M}^{+}, 71 \%\right), 265\left(\mathrm{CH}_{3}\left(\mathrm{CH}_{2}\right)_{7}(\mathrm{CH})_{2}\left(\mathrm{CH}_{2}\right)_{7} \mathrm{CO}^{+}, 100 \%\right)$.

Norspermidine dioleamide ${ }^{48}$ To norspermidine $(1.28 \mathrm{~g}, 9.75 \mathrm{mmol})$ and pyridine $(1.65 \mathrm{~g}, 20.9$ mmol) in benzene $(50 \mathrm{~mL})$, oleoyl chloride $(6.03 \mathrm{~g}, 20.0 \mathrm{mmol})$ was added dropwise at ambient temperature. The solution was stirred for $15 \mathrm{~min}$ and the resulting solid separated by filtration under reduced pressure and then recrystallised from acetone (twice) to give norspermidine dioleamide as a yellow solid (2.63 g, 41\%). Mp 248-256 ${ }^{\circ} \mathrm{C}$ (acetone); ${ }^{1} \mathrm{H}$ NMR (500 MHz; $\mathrm{CDCl}_{3}$ ) $\delta$ 6.78-6.90 $(2 \mathrm{H}$, br s, RCONH), 5.30-5.40 (4H, m, $2 \times \mathrm{CH}=\mathrm{CH}), 3.40\left(4 \mathrm{H}, \mathrm{t}, J 7.0 \mathrm{~Hz}, 2 \times \mathrm{CONHCH}_{2}\right), 2.96$ $\left(4 \mathrm{H}, \mathrm{t}, J 7.0 \mathrm{~Hz}, 2 \times \mathrm{CH}_{2} \mathrm{NH}\right), 2.25\left(4 \mathrm{H}, \mathrm{t}, J 6.5 \mathrm{~Hz}, 2 \times \mathrm{CH}_{2} \mathrm{CO}\right), 2.13(4 \mathrm{H}$, quint, $J 7.0 \mathrm{~Hz}, 2 \times$ 
$\left.\mathrm{NHCH}_{2} \mathrm{CH}_{2}\right), 1.92-2.09\left(8 \mathrm{H}, \mathrm{m}, 4 \times=\mathrm{CHCH}_{2}\right), 1.71-1.80\left(1 \mathrm{H}\right.$, br s, $\left.\mathrm{CH}_{2} \mathrm{NHCH}_{2}\right), 1.66(4 \mathrm{H}$, quint, $J$ $\left.6.5 \mathrm{~Hz}, 2 \times \mathrm{CH}_{2} \mathrm{CH}_{2} \mathrm{CO}\right), 1.18-1.40\left(40 \mathrm{H}, \mathrm{m}, 2 \mathrm{C} \times \mathrm{CH}_{2}\right), 0.86\left(6 \mathrm{H}, \mathrm{t}, J 7.0 \mathrm{~Hz}, 2 \times \mathrm{CH}_{2} \mathrm{CH}_{3}\right) ; \mathrm{m} / z$ $(\mathrm{ES}+) 660\left(\mathrm{M}^{+}, 100 \%\right), 396\left(\mathrm{RCONH}\left(\mathrm{CH}_{2}\right)_{3} \mathrm{NH}\left(\mathrm{CH}_{2}\right)_{3} \mathrm{NH}^{+}, 44 \%\right)$.

\section{Epoxidation reactions}

Two epoxidation methods were used, with either hydrogen peroxide ${ }^{15,49}$ or meta-chloroperbenzoic acid: the highest yielding preparations are described below:

9,10-Epoxystearic acid: To a stirred solution of oleic acid $(90 \% ; 3.57 \mathrm{~g}, 11.3 \mathrm{mmol})$ in toluene $(30 \mathrm{~mL})$ was added formic acid $(95 \% ; 1.9 \mathrm{~mL}, 47.8 \mathrm{mmol})$ and the reaction was heated to $80{ }^{\circ} \mathrm{C}$. Hydrogen peroxide solution was then added dropwise $(54.8 \mathrm{~mL}, 546 \mathrm{mmol} ; 30 \%$ solution). The reaction was then cooled to room temperature, separated and the organic phase washed with water $(3 \times 20 \mathrm{~mL})$, dried $\left(\mathrm{MgSO}_{4}\right)$, and evaporated to give 9,10-epoxystearic acid $(1.38 \mathrm{~g}, 41 \%)$ as a pale yellow waxy solid. Mp 56-59 ${ }^{\circ} \mathrm{C}$ (lit., Mp $59.5{ }^{\circ} \mathrm{C}{ }^{50}$ ); ${ }^{1} \mathrm{H}$ NMR $\left(500 \mathrm{MHz} ; \mathrm{CDCl}_{3}\right) \delta 9.27-$ $11.18(1 \mathrm{H}$, br s, $\mathrm{COOH}), 2.91(2 \mathrm{H}, \mathrm{m}, \mathrm{CHOCH}), 2.35\left(2 \mathrm{H}, \mathrm{t}, J 6.5 \mathrm{~Hz}, \mathrm{CH}_{2} \mathrm{CO}_{2} \mathrm{H}\right), 1.64$ (2H, quint, $\left.J 6.5 \mathrm{~Hz}, \mathrm{CH}_{2} \mathrm{CH}_{2} \mathrm{CO}_{2} \mathrm{H}\right), 1.42-1.56\left(4 \mathrm{H}, \mathrm{m}, \mathrm{CH}_{2} \mathrm{CHOCHCH}_{2}\right), 1.16-1.45\left(20 \mathrm{H}, \mathrm{m}, 10 \times \mathrm{CH}_{2}\right), 0.87$ $\left(3 \mathrm{H}, \mathrm{t}, J 7.0 \mathrm{~Hz}, \mathrm{CH}_{2} \mathrm{CH}_{3}\right) ; \mathrm{m} / z$ (ES-) 297 ([M-H]', 100\%).

9,10-Epoxystearate propyl diester diol To a stirred solution of oleate propyl diester diol $(6.08 \mathrm{~g}, 10.0 \mathrm{mmol})$ in toluene $(5 \mathrm{~mL})$ was added formic acid $(0.74 \mathrm{~mL}, 20 \mathrm{mmol})$. Hydrogen peroxide solution was then added dropwise ( $2 \mathrm{~mL}, 20 \mathrm{mmol} ; 30 \%$ solution), followed by raising the temperature slowly to $80{ }^{\circ} \mathrm{C}$. The reaction was cooled to room temperature, separated and the organic phase washed with water $(2 \times 50 \mathrm{~mL})$, dried $\left(\mathrm{MgSO}_{4}\right)$, and evaporated to give 9,10epoxystearate propyl diester diol $(3.18 \mathrm{~g}, 50 \%$; 50\% purity with oleate propyl diester diol remaining) as a pale yellow wax/syrup. ${ }^{1} \mathrm{H} \mathrm{NMR}\left(500 \mathrm{MHz} ; \mathrm{CDCl}_{3}\right) \delta 4.14(4 \mathrm{H}, \mathrm{t}, J 6.5 \mathrm{~Hz}, 2 \times$ $\left.\mathrm{CH}_{2} \mathrm{OCO}\right), 2.91(4 \mathrm{H}, \mathrm{m}, 2 \times \mathrm{CHOCH}), 2.33\left(4 \mathrm{H}, \mathrm{m}, 2 \times \mathrm{CH}_{2} \mathrm{CO}_{2}\right), 1.96\left(2 \mathrm{H}, \mathrm{m}, \mathrm{CH}_{2} \mathrm{CH}_{2} \mathrm{OCO}\right)$, 1.55-1.70 (8H, m, $\left.4 \times \mathrm{CH}_{2}\right), 1.16-1.54\left(40 \mathrm{H}, \mathrm{m}, 20 \times \mathrm{CH}_{2}\right), 0.91\left(6 \mathrm{H}, \mathrm{t}, J 6.7 \mathrm{~Hz}, 2 \times \mathrm{CH}_{2} \mathrm{CH}_{3}\right)$.

Orcyl-di-9,10-epoxystearate. To orcyl dioleate $(1.26 \mathrm{~g}, 1.93 \mathrm{mmol})$ in chloroform $(20 \mathrm{~mL})$ $m$ CPBA (2.21 g, 9.86 mmol; 77\% purity) was added. The mixture was stirred at room temperature for $1.5 \mathrm{~h}$. The resulting precipitate of meta-chlorobenzoic acid by-product was removed by filtration, and the filtrate was washed with $5 \%$ sodium hydrogen carbonate, dried $\left(\mathrm{MgSO}_{4}\right)$ and the solvent removed in vacuo to yield orcyl-di-9,10-epoxystearate $(1.15 \mathrm{~g}, 87 \%)$ as a yellow oil. ${ }^{1} \mathrm{H}$ NMR (500 MHz; $\left.\mathrm{CDCl}_{3}\right) \delta 6.79(2 \mathrm{H}, \mathrm{s}, \mathrm{ArH}), 6.71(1 \mathrm{H}, \mathrm{s}, \mathrm{ArH}), 2.92(4 \mathrm{H}, \mathrm{m}, 2 \times \mathrm{CHOCH}), 2.53$ $\left(4 \mathrm{H}, \mathrm{t}, J 7.5 \mathrm{~Hz}, 2 \times \mathrm{CH}_{2} \mathrm{CO}_{2}\right), 2.36\left(3 \mathrm{H}, \mathrm{s}, \mathrm{ArCH}_{3}\right), 1.74\left(4 \mathrm{H}\right.$, quint, $\left.J 7.5 \mathrm{~Hz}, 2 \times \mathrm{CH}_{2} \mathrm{CH}_{2} \mathrm{CO}_{2}\right)$, $1.51\left(8 \mathrm{H}, \mathrm{m}, 2 \times \mathrm{CH}_{2} \mathrm{CHOCHCH}_{2}\right), 1.18-1.47\left(40 \mathrm{H}, \mathrm{m}, 20 \times \mathrm{CH}_{2}\right), 0.90(6 \mathrm{H}, \mathrm{t}, J 7.0 \mathrm{~Hz}, 2 \times$ $\left.\mathrm{CH}_{2} \mathrm{CH}_{3}\right) ; m / z(\mathrm{ES}+) 685\left(\mathrm{M}^{+}, 100 \%\right)$. 
Resorcyl-di-9,10-epoxystearate. To resorcyl dioleate $(4.78 \mathrm{~g}, 7.48 \mathrm{mmol})$ in chloroform (40 $\mathrm{mL}) \mathrm{mCPBA}(9.18 \mathrm{~g}, 41.0 \mathrm{mmol} ; 77 \%$ purity) was added. The mixture was stirred at room temperature for $1.5 \mathrm{~h}$. The resulting precipitate of meta-chlorobenzoic acid by-product was removed by filtration, and the filtrate was washed with $5 \%$ sodium hydrogen carbonate, dried $\left(\mathrm{MgSO}_{4}\right)$ and the solvent removed in vacuo to yield resorcyl-di-9,10-epoxystearate (3.86 g, 77\%) as a pale yellow wax. Mp 27-33 ${ }^{\circ} \mathrm{C} ;{ }^{1} \mathrm{H}-\mathrm{NMR}\left(500 \mathrm{MHz} ; \mathrm{CDCl}_{3}\right) \delta 7.37(1 \mathrm{H}, \mathrm{t}, J 8.5 \mathrm{~Hz}, \mathrm{ArH}), 6.97$ (2H, d, $J 8.5$ $\mathrm{Hz}, \mathrm{Ar} H), 6.92(1 \mathrm{H}, \mathrm{s}, \mathrm{ArH}), 2.88-2.96(4 \mathrm{H}, \mathrm{m}, \mathrm{CHOCH}), 2.52\left(4 \mathrm{H}, \mathrm{t}, J 6.5 \mathrm{~Hz}, 2 \times \mathrm{CH}_{2} \mathrm{CO}_{2}\right)$, 1.67-1.78 (4H, m, $\left.2 \times \mathrm{CH}_{2} \mathrm{CH}_{2} \mathrm{CO}_{2}\right), 1.48-1.58\left(8 \mathrm{H}, \mathrm{m}, 2 \times \mathrm{CH}_{2} \mathrm{CHOCHCH}_{2}\right)$ 1.18-1.48 (40H, m, $\left.20 \times \mathrm{CH}_{2}\right), \quad 0.84-0.95\left(6 \mathrm{H}, \quad \mathrm{m}, 2 \times \mathrm{CH}_{2} \mathrm{CH}_{3}\right) ; \quad m / z \quad(\mathrm{CI}+) \quad 671 \quad\left(\mathrm{M}^{+}, \quad 59 \%\right), 281$ $\left(\mathrm{CH}_{3}\left(\mathrm{CH}_{2}\right)_{7} \mathrm{CHOCH}\left(\mathrm{CH}_{2}\right)_{7} \mathrm{CO}^{+}, 100 \%\right)$.

Norspermidyl di-9,10-epoxystearamide. To a stirred solution of norspermidine dioleamide $(0.970 \mathrm{~g}, 1.47 \mathrm{mmol})$ in toluene $(20 \mathrm{~mL})$ was added formic acid $(95 \% ; 3.3 \mathrm{~mL}, 83.1 \mathrm{mmol})$, and the reaction was heated to $80{ }^{\circ} \mathrm{C}$. Hydrogen peroxide solution was added dropwise (5.95 g, $52.5 \mathrm{mmol}$; $30 \%$ solution). The reaction was then cooled to ambient temperature, separated and the organic phase washed with water $(3 \times 30 \mathrm{~mL})$, dried $\left(\mathrm{MgSO}_{4}\right)$, and evaporated to give norspermidyl di9,10-epoxystearamide $(0.61 \mathrm{~g}, 60 \%)$ as a yellow paste. ${ }^{1} \mathrm{H}-\mathrm{NMR}\left(500 \mathrm{MHz} ; \mathrm{CDCl}_{3}\right) \delta 6.58-7.08$ $(2 \mathrm{H}$, br s, RCONH$), 3.46\left(4 \mathrm{H}, \mathrm{t}, J 6.0 \mathrm{~Hz}, 2 \times \mathrm{CONHCH}_{2}\right), 2.94-3.00\left(4 \mathrm{H}, \mathrm{m}, \mathrm{CH}_{2} \mathrm{NHCH}_{2}\right), 2.87-$ $2.97(4 \mathrm{H}, \mathrm{m}, \mathrm{CHOCH}), 2.29\left(4 \mathrm{H}, \mathrm{t}, J 6.5 \mathrm{~Hz}, 2 \times \mathrm{CH}_{2} \mathrm{CONH}\right), 2.11$ (4H, quint, $J 6.5 \mathrm{~Hz}, 2 \times$ $\left.\mathrm{NHCH}_{2} \mathrm{CH}_{2}\right), 1.74-1.85\left(1 \mathrm{H}\right.$, br s, $\left.\mathrm{CH}_{2} \mathrm{NHCH}_{2}\right), 1.60-1.69$ (4H, quint, $J 6.5 \mathrm{~Hz}, 2 \times$ $\left.\mathrm{CH}_{2} \mathrm{CH}_{2} \mathrm{CONH}\right), 1.32-1.44\left(8 \mathrm{H}, \mathrm{m}, \mathrm{CH}_{2} \mathrm{CHOCHCH}_{2}\right), 1.18-1.32\left(40 \mathrm{H}, \mathrm{m}, 20 \times \mathrm{CH}_{2}\right), 0.86(6 \mathrm{H}, \mathrm{t}, J$ $\left.7.0 \mathrm{~Hz}, \mathrm{CH}_{2} \mathrm{CH}_{3}\right) ; m / z(\mathrm{ES}+) 692\left(\mathrm{M}^{+}, 25 \%\right)$.

\section{Amine-epoxy Reactions}

For the homopolymerization of 9,10-epoxystearic acid, 1 eq. and PPD/NEt 3 initiator ( 0.05 eq.) were mixed, placed in a glass sample tube and heated in an oven at $100{ }^{\circ} \mathrm{C} / 150{ }^{\circ} \mathrm{C} / 200{ }^{\circ} \mathrm{C}$ for $1 \mathrm{~h}$ or $5 \mathrm{~h}$.

For the epoxy dioleates, two amine curing agents were used, (i) diethylenetriamine (DET) and (ii) p-phenylenediamine (PPD) using the following procedures. The diepoxy compounds and diamine curing agents were mixed in 1:1 equivalents at ambient temperature until a homogeneous mixture was obtained. In some cases it was left to react for up to seven days (0.6 Ms) and in others it was heated in an oven at $150{ }^{\circ} \mathrm{C}$ for $16 \mathrm{~h}$.

\section{Anhydride Curing Reactions}


Initially, the anhydride curing step using cis-1,2-cyclohexanedicarboxylic anhydride $(\mathrm{CH})$ with triethylamine $\left(\mathrm{NEt}_{3}\right)$ as initiator was applied after esterification and epoxidation. The epoxidized monomer, $\mathrm{CH}$ and $\mathrm{NEt}_{3}$ were mixed in molar ratios of $0.5 / 0.5 / 0.0085$, respectively. The curing time and temperature were prompted by the work of Nicolau et al. ${ }^{15}$ which used $165{ }^{\circ} \mathrm{C}$ for 3 hours and by Rosch et al. ${ }^{51}$, who used $200{ }^{\circ} \mathrm{C}$ for 1 hour. Products were stored in a vacuum desiccator at room temperature.

In subsequent experiments, the epoxidized but unesterfied oleic acid (9,10-epoxystearic acid) was reacted with anhydride curing agent. The reaction product was subsequently mixed with one of the diols (1,3-propanediol, orcinol or resorcinol) in a round bottom flask in a molar ratio of 2:1. The mixture was raised to $160{ }^{\circ} \mathrm{C}$ by use of a silicone oil bath and $0.01 \mathrm{~mL}$ of titanium (IV) n-butoxide was added to the mixture ${ }^{52}$. Reaction took place for 1 hour after which the temperature was decreased to $120^{\circ} \mathrm{C}$ for 30 minutes in order to remove all water produced from the esterification reaction. Solubility tests were performed on the polymers thus obtained.

\section{Interaction with smectite clays}

XRD was used to assess swelling in order to explore the viability of forming polymer-clay nanocomposites by in-situ polymerization. Samples of (i) clay, (ii) clay + methanol and (iii) clay + monomer + methanol were made using $1 \mathrm{~g}$ of monomer, $1 \mathrm{~g}$ of clay and $10 \mathrm{~mL}$ of methanol. All the samples were exposed for $10 \mathrm{~min}$ to the ultrasonicator at a duty cycle 0.5 with constant amplitude of $60 \%$ with the exception of organoclay which was hand mixed. A control with solvent and clay alone were used to establish the effect of solvent on the clay. All samples were dried at $60{ }^{\circ} \mathrm{C}$ overnight to remove solvent.

Five different clays were used: (i) Nanofil $116 \AA$, an unmodified montmorillonite (Rockwood Company, Southern Clay Products Inc. Texas USA) (ii) Cloisite $\AA$ 10A which is modified with a benzyl (hydrogenated tallow alkyl)dimethyl, salt (Rockwood Company, Southern Clay Products Inc. Texas USA), (iii) Nanofil 116 treated with aminolauric acid (ALA modified), (iv) Nanofil 116 treated with diethylenetriamine (DET modified) and (v) Nanofil 116 treated with p-phenylenediamine (PPD modified). Clays (iii), (iv) and (v) were prepared in this laboratory by $\mathrm{Mr}$ Illya Litvinov following the procedure recommended by Akela et al. ${ }^{53}$ A Siemens D500 diffractometer with Bragg-Brentano geometry and silicon (111) pre-sample monochromator was used with $\mathrm{Cu} \mathrm{K \alpha} \alpha_{1}$ radiation with wavelength $1.54056 \AA$.

\section{Results and discussion}

Products of homopolymerisation of epoxystearic acid 
The epoxidation of oleic acid was carried out as described in the experimental and below. ${ }^{46}$ Homopolymerisation was carried out using PPD and $\mathrm{NEt}_{3}$. The extent of epoxide ring opening was estimated using ${ }^{1} \mathrm{H}-\mathrm{NMR}$ spectroscopy by dividing the integral of the signal from remaining epoxy protons over the integral from the $\mathrm{CH}_{2} \mathrm{COOH}$ signal (equivalent to two protons) and then subtracting that value from one. Results for homopolymerisation of epoxystearic acid as a function of initiator, curing temperature and curing time (Table 1) showed that samples heated at $200{ }^{\circ} \mathrm{C}$ for 5 hours formed non-sticky solids. They were insoluble in all solvents tested and could be heated above $200{ }^{\circ} \mathrm{C}$ without melting, indicative of substantial curing. Materials made with PPD were noticeably harder and more brittle than the $\mathrm{NEt}_{3}$ equivalent, which was more rubbery.

Increasing the temperature from $100{ }^{\circ} \mathrm{C}$ to $150{ }^{\circ} \mathrm{C}$ and extending the reaction time from 1 to 5 hours at $100{ }^{\circ} \mathrm{C}$ produced a substantial rise in epoxy ring opening. This time-temperature dependence of ring opening agrees with literature reports ${ }^{34}$. As with polymers produced from diepoxides (vide infra), samples that were cured to a greater extent had a darker colour a trend that was much less pronounced with $\mathrm{NEt}_{3}$ initiation which gave transparent, light orange-brown coloured materials.

Samples obtained as waxes had similar texture and softness to epoxystearic acid, reaction conditions of $100{ }^{\circ} \mathrm{C}$ for 1 hour being insufficient to completely melt the resin thus restricting mobility and hence the extent of ring opening. Samples obtained as viscous liquids appeared to become more viscous and less soluble as percentage ring opening increased, fully cured resin being completely insoluble ${ }^{19}$.

Table 1. Homopolymerisation of epoxystearic acid

\begin{tabular}{|c|c|c|c|c|c|}
\hline Initiator & Time/h & Temp/ ${ }^{\circ} \mathbf{C}$ & $\begin{array}{c}\% \text { Ring } \\
\text { opening }\end{array}$ & Colour & Form \\
\hline PPD & 1 & 100 & 52 & Dark brown & Soft wax \\
\hline PPD & 1 & 150 & 92 & Dark brown & Viscous liquid \\
\hline PPD & 1 & 200 & 99 & Dark brown & Viscous liquid \\
\hline PPD & 5 & 100 & 70 & Dark brown & Viscous liquid \\
\hline PPD & 5 & 150 & 97 & Dark brown & Viscous liquid \\
\hline PPD & 5 & 200 & N/A & Dark brown & Brittle solid \\
\hline $\mathrm{NEt}_{3}$ & 1 & 100 & 49 & Pale yellow & Soft wax \\
\hline $\mathrm{NEt}_{3}$ & 1 & 150 & 90 & Brown-orange & Viscous liquid \\
\hline $\mathrm{NEt}_{3}$ & 1 & 200 & 98 & Brown-orange & Viscous liquid \\
\hline $\mathrm{NEt}_{3}$ & 5 & 100 & 76 & Pale yellow & Viscous liquid \\
\hline $\mathrm{NEt}_{3}$ & 5 & 150 & 97 & Brown-orange & Viscous liquid \\
\hline $\mathrm{NEt}_{3}$ & 5 & 200 & N/A & Brown-orange & Rubbery solid \\
\hline
\end{tabular}


Thus while homopolymerisation of epoxystearic acid requires fewer supplementary reagents and one less reaction step, high temperature heating periods are a disadvantage. In reports initiation by UV irradiation shows promise ${ }^{54}$. Here, subsequent work focused on epoxidized dimers which offer a family of promising resins with considerable scope for development.

Figure 1 shows the ${ }^{1} \mathrm{H}$ NMR spectrum of the product of polymerization in the presence of $\mathrm{NEt}_{3}$ at $150{ }^{\circ} \mathrm{C}$ for 5 hours.

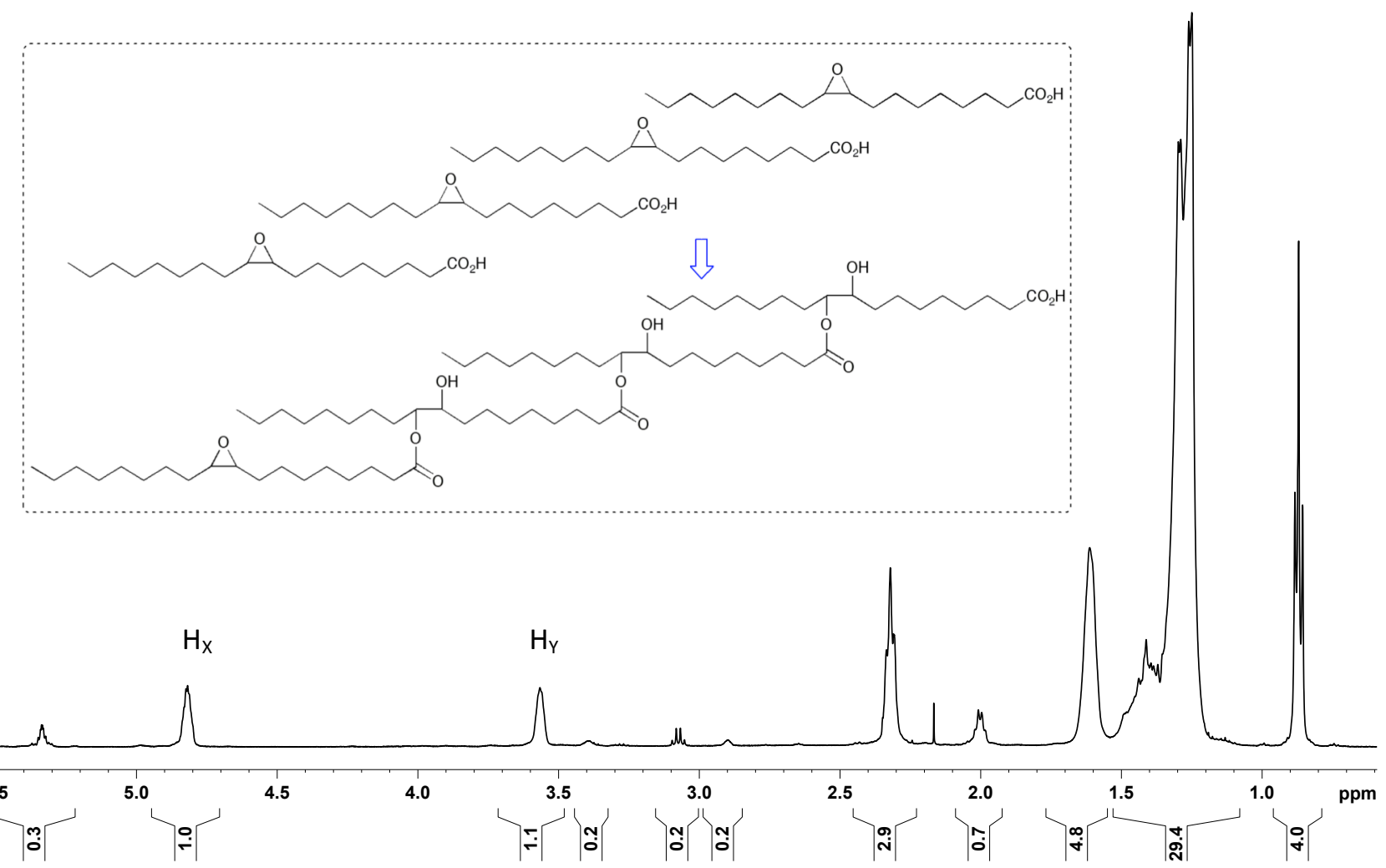

Figure 1. The ${ }^{1} \mathrm{H}$ NMR spectrum (in $\mathrm{CDCl}_{3}$ ) of the product of polymerization of epoxystearic acid in the presence of $\mathrm{NEt}_{3}$ at $150{ }^{\circ} \mathrm{C}$ for 5 hours. A schematic presentation of the corresponding polymerization process is also shown.

The product of polymerization shows two distinct signals at $4.82 \mathrm{ppm}$ and $3.57 \mathrm{ppm}$. These are characteristic for $>\mathrm{CH}_{\mathrm{X}}-\mathrm{O}-\mathrm{CO}-$ and $>\mathrm{CH}_{\mathrm{Y}}-\mathrm{O}$ - protons, respectively. Based on these observations, the following structure is suggested for the product of polymerization:

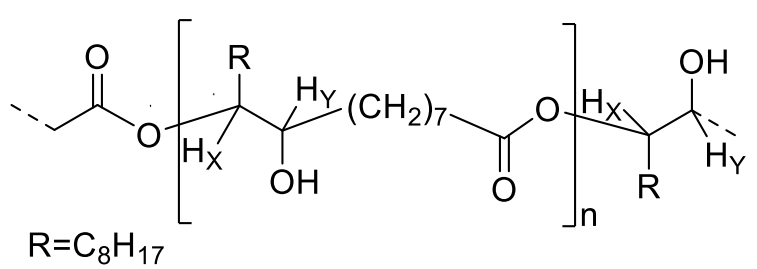

A schematic presentation of the corresponding polymerization process is presented in the inset of Figure 1. 


\section{Monomer synthesis: di-esters and diamide}

The diesterification reaction between 1,3-propanediol and oleic acid using DCC/DMAP proceeded in good yield and the ${ }^{1} \mathrm{H}$ NMR spectroscopy characterisation data of the product (Figure 2) was identical to that previously reported ${ }^{47}$. Orcyl and resorcyl dioleate were also generated using DCC/DMAP couplings and were characterised using ${ }^{1} \mathrm{H}$ NMR and mass spectrometry (MS). Norspermidine dioleamide ${ }^{48}$ was prepared using standard procedures [e.g. ref 31] from oleoyl chloride, norspermidine and pyridine and was characterised by ${ }^{1} \mathrm{H}$ NMR and MS. Use of oleoyl chloride and direct coupling with polyamines is a more atom efficient method for amide synthesis than via Steglich couplings which produces urea waste. Future work will also focus on ester synthesis avoiding Steglich couplings. It is possible that due to the higher nucleophilicity of the secondary amine, secondary amide formation could also occur. However, the primary amines are less sterically hindered. Previous work has indicated that triamide formation requires higher reaction temperatures and that the diamide is the kinetically favoured product ${ }^{49}$. The dioleamide product (Figure 2) was recrystallised twice: MS data of this purified material showed a peak at $\mathrm{m} / \mathrm{z}$ 924 , corresponding to the triamide with a relative abundance of $<2 \%$ which was almost negligible compared to the dioleamide molecular ion peak at 660 . The diamide has previously been investigated as a soil hydrophobic agent ${ }^{48}$.

Some samples of orcyl and resorcyl dioleate were purified using column chromatography while for norspermidine-dioleamide, recrystallisation was used. Residual $N, N$ '-dicyclohexylurea (a side-product of the DCC coupling reaction) and oleic acid could reduce the extent of polymerisation: oleic acid has only one olefin moiety per molecule and may thus induce termination. Removal of oleic acid from crude orcyl and resorcyl dioleate may be important due to the potential plasticizing effect of oleic acid.

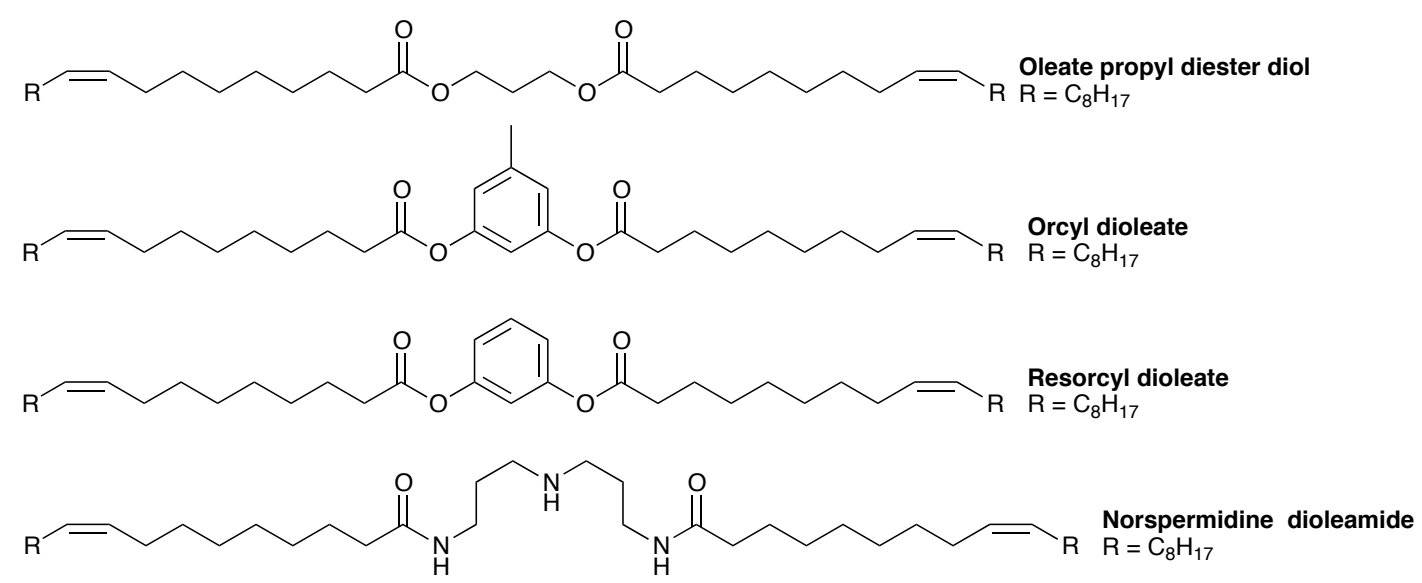

Figure 2. Di-esters and diamide synthesised 


\section{Monomer synthesis: epoxidation of oleic acid, the di-esters and diamide}

Initially hydrogen peroxide was used at high temperature to carry out the epoxidation as previously reported ${ }^{51}$. The epoxy group is not strongly characterized in the infrared spectrum ${ }^{55}$ so conversion of oleic acid and its di-ester to epoxides was monitored using ${ }^{1} \mathrm{H}$ NMR spectroscopy: epoxidation was indicated by disappearance of the alkene $\mathrm{CHs}$ at $\sim 5.3 \mathrm{ppm}$ and appearance of a peak at $\sim 2.9 \mathrm{ppm}$ which corresponded to the $\mathrm{CH}$ protons of the epoxy group. Oleic acid was epoxidized to give epoxide A (Figure 3 ) in high purity and $41 \%$ yield. ${ }^{50}$ However, using hydrogen peroxide and a similar procedure, the epoxidized di-ester $\mathbf{B}$ was formed in 50\% yield, and 55\% purity (oleate propyl diester diol remained from analysis of the ${ }^{1} \mathrm{H}$ NMR spectrum). Using analogous procedures orcyl dioleate and resorcyl dioleate were fully epoxidized to give epoxides $\mathbf{C}$ and $\mathbf{D}$ in $75 \%$ and $69 \%$ yields, respectively. During epoxidation in the presence of formic acid, the hydrogen peroxide may also cleave the ester bond, however no ${ }^{1} \mathrm{H}$ NMR signals corresponding to the diols were observed. Formation of the epoxides was further confirmed by MS. Epoxidation of norspermidine-dioleamide to give $\mathbf{E}$ in good purity using $\mathrm{H}_{2} \mathrm{O}_{2}$ was achieved in $60 \%$ yield.

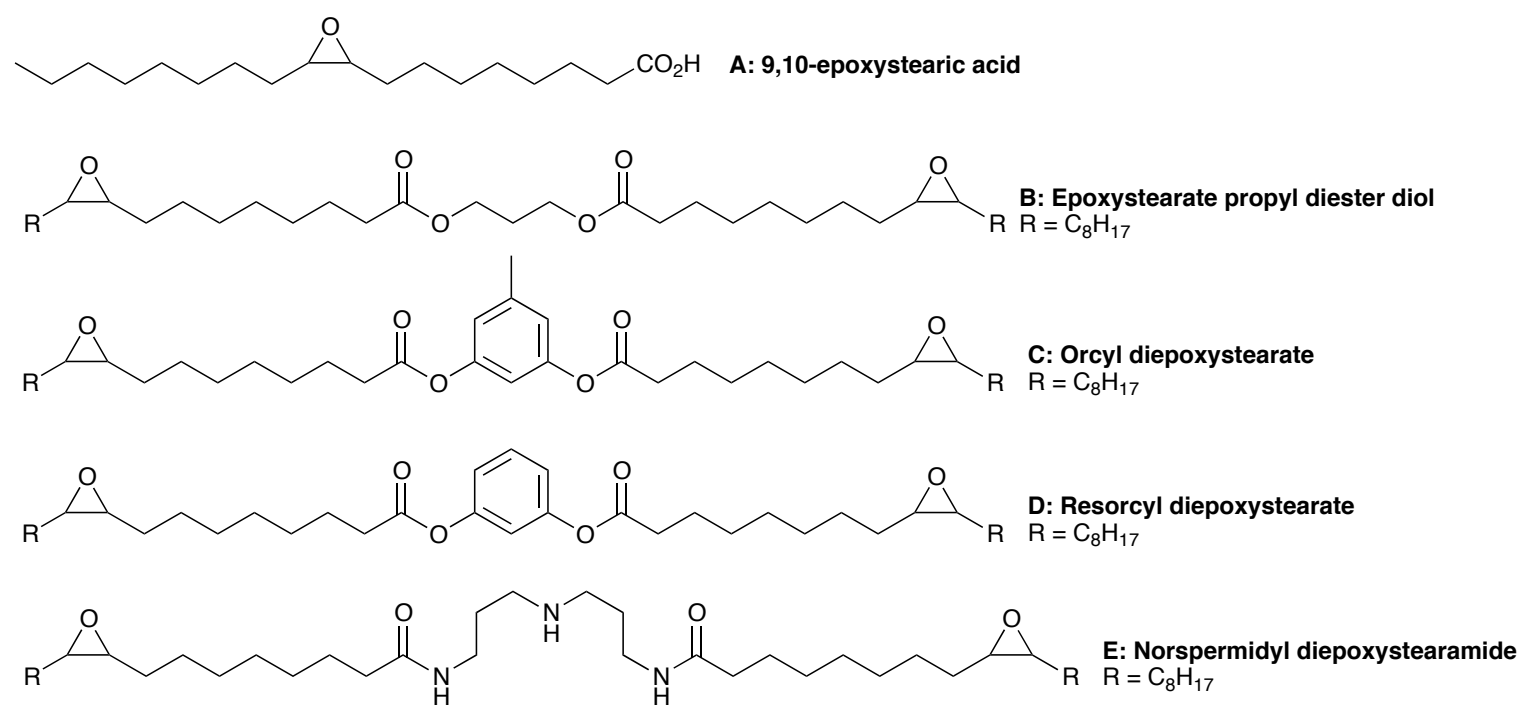

Figure 3. Epoxides synthesised

mCPBA was also employed as an alternative epoxidising agent to $\mathrm{H}_{2} \mathrm{O}_{2}$ for the orcyl and resorcyl dioleates and the reaction can be performed at ambient temperature. Epoxidation by mCPBA of the orcyl and resorcyl dioleates gave $\mathbf{C}$ and $\mathbf{D}$ in $87 \%$ and $77 \%$ yields respectively, $12 \%$ and $8 \%$ higher yields than when using hydrogen peroxide. 


\section{Anhydride curing of epoxystearic acid followed by esterification}

The products of epoxidized oleates with a cyclic anhydride as curing agent are neither crosslinked $^{15}$, rubber-like or highly flexible ${ }^{51}$ according to the literature. This was confirmed with epoxystearic acid $\mathbf{A}$ before using the di-esters for the reaction. Curing reactions were carried out at $165^{\circ} \mathrm{C}$ for 3 hours, as in Nicolau's work ${ }^{15}$, and $200{ }^{\circ} \mathrm{C}$ for 1 hour as in Rosch's work ${ }^{51}$. It should be noted that the carboxylic acid group can also react with the anhydride leading to ring opening and subsequent polymerization.

Infrared spectra of reaction products of epoxystearic acid and cis-1,2-cyclohexanedicarboxylic anhydride under these conditions $\left(165^{\circ} \mathrm{C}\right.$ for 3 hours $/ 200{ }^{\circ} \mathrm{C}$ for 1 hour) were similar (Figure 4). Peaks in the region of $1735-1729 \mathrm{~cm}^{-1}$ are attributed to the stretching vibrations of the $\mathrm{C}=\mathrm{O}$ of the carboxylic acid group while those at 1250 and $1170 \mathrm{~cm}^{-1}$ correspond to the C-O-C bonds of the ester linkages. Peaks around $3000 \mathrm{~cm}^{-1}$ represent the $\mathrm{CH}_{2}$ asymmetric and symmetric stretching vibrations. 

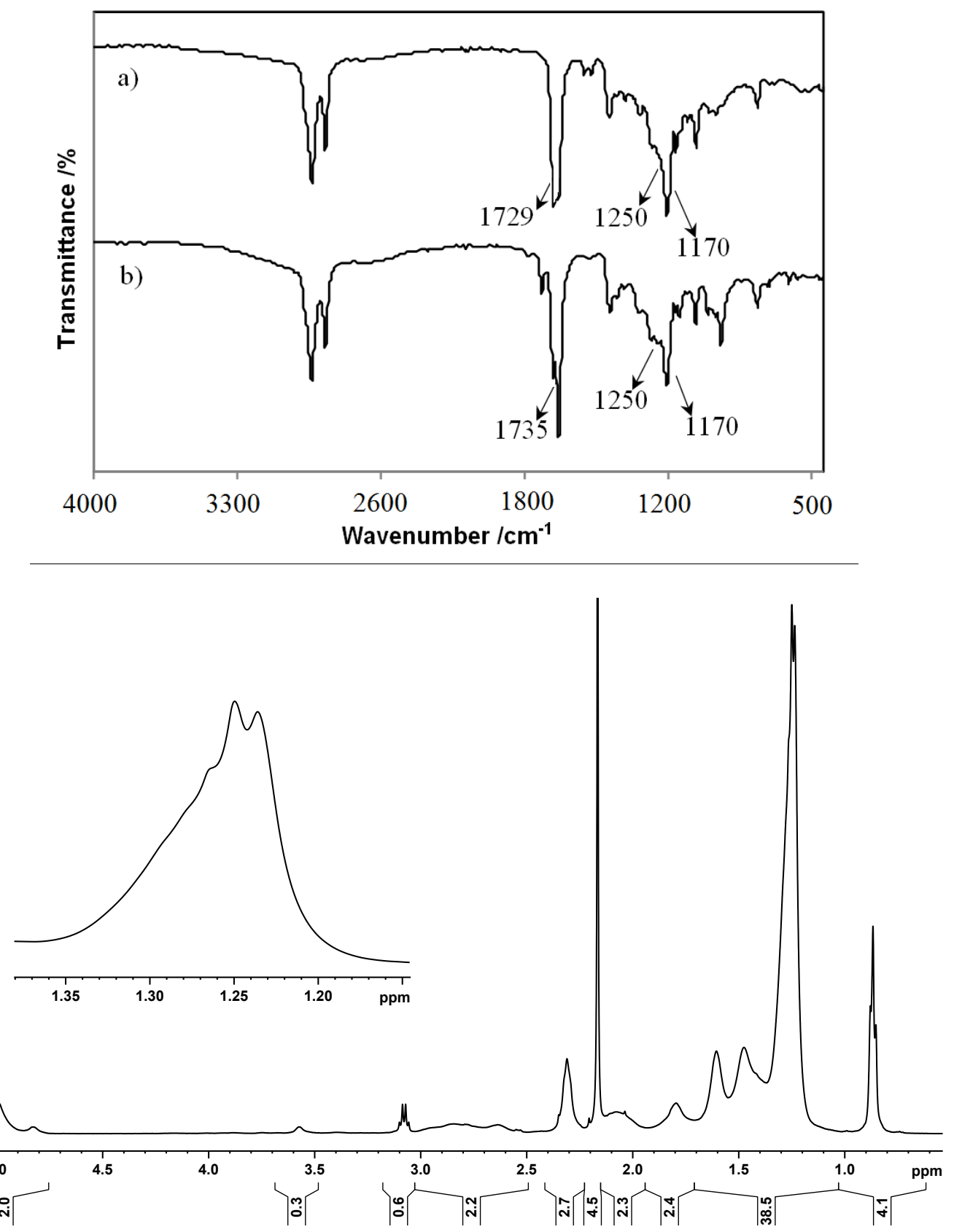

Figure 4. FT-IR of the product of the reaction of epoxystearic acid and cis-1,2cyclohexanedicarboxylic anhydride from a) $165^{\circ} \mathrm{C}$ for $3 \mathrm{~h}$ and b) $200{ }^{\circ} \mathrm{C}$ for $1 \mathrm{~h}$ (above) and the ${ }^{1} \mathrm{H}$ NMR spectrum (in $\mathrm{CDCl}_{3}$ ) of the product heated at $165^{\circ} \mathrm{C}$ for $3 \mathrm{~h}$ (below).

In the ${ }^{1} \mathrm{H}$ NMR spectrum of anhydride-cured products obtained at $165{ }^{\circ} \mathrm{C}$ from epoxystearic acid (Figure 4), signals at $\sim 5 \mathrm{ppm}$ were attributed to the $\mathrm{H}_{\mathrm{A}}$ protons of the ester linkage formed by the incorporation of the anhydride. Three broad signals can be identified at 5.10, 4.99 and $4.83 \mathrm{ppm}$ with the integral intensity ratio of approximately $1: 12: 2$. The signals at 4.83 and $3.57 \mathrm{ppm}$ are due to the homopolymer of the epoxystearic acid (Figure 1). The smallest signal at 5.10 ppm may be 
due to the end-group $>\mathrm{CH}_{\mathrm{A}} \mathrm{N}^{+}$or $>\mathrm{CH}_{\mathrm{A}} \mathrm{O}$ protons, although further studies are needed in order to verify the origin of this signal. Broad overlapping signals between 2.5-3 ppm are assigned to the $\mathrm{CH}$ protons of the 1,2-substituted cyclohexane fragment in the anhydride-cured polymer, although a fraction of these is due to unopened oxirane protons at $2.90 \mathrm{ppm}$. The other signals are consistent with the material reported by Nicolau ${ }^{15}$.

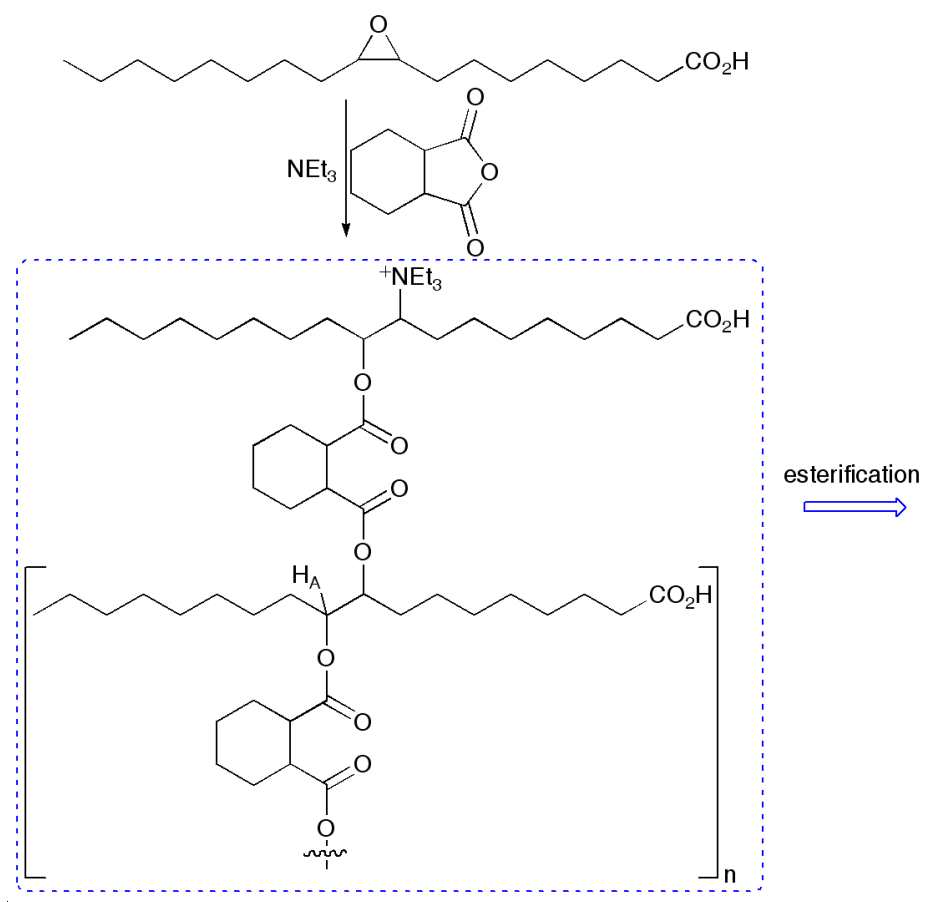

Figure 5. The scheme of the reaction of epoxystearic acid with anhydride ( $n=$ degree of polymerization).

The previously suggested scheme ${ }^{15}$ of anhydride curing reaction from oleic acid is shown in Figure and is in agreement with our results described above, although the presence of the ${ }^{+} \mathrm{NEt}_{3}$ end group may need further verification as the its replacement by the hydroxyl group cannot be ruled out. The products were soluble in chloroform, DMSO, acetone, toluene and DMF, indicating they were not crosslinked.

It was decided to investigate whether the acid groups could be esterified after the epoxidation step, effectively giving a diol the role of curing agent. The products of epoxidized oleic acid and anhydride obtained at $165{ }^{\circ} \mathrm{C}$ (being un-crosslinked according to ${ }^{1} \mathrm{H}$ NMR and FT-IR), were then esterified at $160{ }^{\circ} \mathrm{C}$ with titanium (VI) n-butoxide ${ }^{53}$ using 3 different diols: resorcinol, orcinol and 1,3-propanediol, essentially making esterification the last, rather than the first step. When 1,3propanediol was used, there was no change in the waxy appearance of the product of epoxidized oleic acid and anhydride. When orcinol was employed, upon cooling the product solidified after 1 hour at ambient temperature. During the esterification reaction with resorcinol, the product solidified after 7 minutes producing a dark-brown polymer. 
After orcinol esterification, no solubility was observed in toluene but the material was partially soluble in $\mathrm{CDCl}_{3}$ and DMSO. For the reaction product from resorcinol, there was no detectable solubility in these solvents or in toluene after 1 week. The absence of solubility suggested that crosslinking of the polymer occurred when esterified. Thus the pathway of using a diol to crosslink an epoxystearic acid previously dimerised by anhydride emerges as a route to a family of thermosetting polymers much deserving of further development.

Figure 6 shows the solid-state ${ }^{13}$ C CPMAS TOSS NMR spectrum for resorcinol esterified resin which was consistent with the conjugation of resorcinol to the polymer. In the area of carboxylic carbons between 166-183 ppm, the relatively strong signal at $174 \mathrm{ppm}$ can be assigned to carboxylic carbons attached to the cyclohexane ring (e.g., 173.9 ppm in dimethyl cyclohexane-1,2dicarboxylate, ${ }^{56}$ while the signal at $167 \mathrm{ppm}$ is characteristic for carboxylic carbons attached to the benzene ring. ${ }^{57}$ The signal at 183 ppm is due to the acid $\mathrm{CO}_{2} \mathrm{H}$ carbon attached to the alkyl chain (e.g., $180.3 \mathrm{ppm}$ in octanoic acid ${ }^{58}$ ), which is attributed to unesterified $\mathrm{CO}_{2} \mathrm{H}$ groups in the resorcinol esterified resin. The signal due to the resorcyl quaternary $\mathrm{C}-\mathrm{O}$ carbons is observed at 152-160 ppm, with the signal maximum at $158 \mathrm{ppm}$. As confirmed by the CPMAS TOSS NQS experiments, other signals due to the protonated aromatic resorcyl carbons are at $\sim 129 \mathrm{ppm}$ (meta to aryl C-O) and $\sim 108 \mathrm{ppm}$ (ortho/para to aryl C-O). Aliphatic $>\mathrm{CH}-\mathrm{O}{ }^{13} \mathrm{C}$ NMR signals can be observed at $74.3 \mathrm{ppm}$. The relatively small signals at 64.9 and $19.9 \mathrm{ppm}$ are assigned to the $\mathrm{CH}_{2} \mathrm{O}-$ and $\mathrm{Me}-\mathrm{CH}_{2-}$ carbons of titanium (IV) $n$-butoxide, respectively. ${ }^{59}$ The cyclohexyl $\mathrm{CH}$ signals are observed at $45 \mathrm{ppm}$ and remaining aliphatic carbons are at $\sim 14-35 \mathrm{ppm}$. 


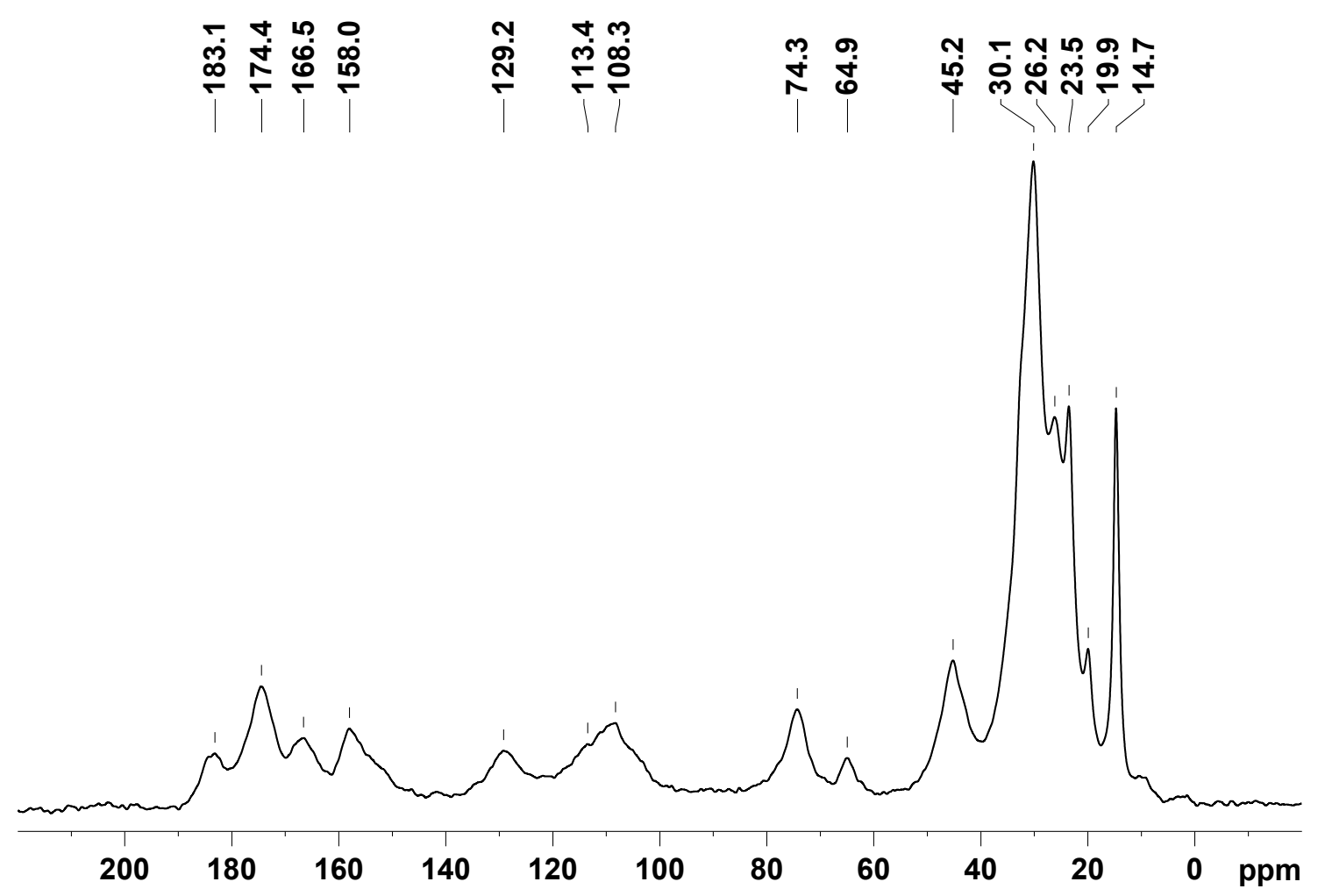

Figure 6. The solid state CPMAS TOSS ${ }^{13} \mathrm{C}$ NMR spectrum for epoxystearic acid reacted with cis1,2-cyclohexanedicarboxylic anhydride and then esterified with resorcinol.

\section{Amine curing of epoxy distearates.}

Initially, attempts were made to polymerize diepoxystearates (Figure 3: epoxides B,C and D) at room temperature using diethylenetriamine (DET) and $p$-phenylenediamine (PPD) curing agents (Figure 7) with a 1:1 ratio of the amine and epoxy group.<smiles>NCCNCCN</smiles>

diethylenetriamine(DET)

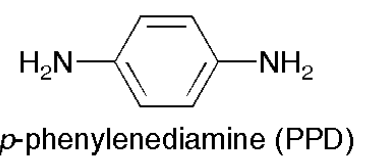

Figure 7. Amine curing agents

Secondary and primary amines are capable of forming a linkage to one and two epoxy groups respectively. Hence one DET monomer can in principle link to five epoxy groups and one PPD monomer can link four epoxy groups. PPD as an aromatic amine, typically produces cured resins with high chemical and thermal resistance properties but tends to require long cure cycles at high temperatures. The FTIR spectra of the products were similar. Absorptions in the region of 3350- 
$3400 \mathrm{~cm}^{-1}$ can be attributed to the N-H bond vibration of the amine group from the curing agents, indicating that there is residual unreacted amine. The broadening of the signal in the region of 3200$3570 \mathrm{~cm}^{-1}$ could also be ascribed to the stretching vibrations of -OH groups from the opening of the oxirane ring in the curing reaction.

In the room temperature cured materials the ${ }^{1} \mathrm{H}$ NMR spectra showed weak signals from residual epoxy group protons even when all curing agent appeared to have been consumed; products were all in the form of waxes and were soluble in chloroform and acetone.

Epoxidized resorcinol (epoxide D) and 1,3- propanediol diesters of oleic acid cured with PPD and DET which had not been subjected to column purification were then heated at $150{ }^{\circ} \mathrm{C}$ for 16 hours. They formed hard solids which were insoluble in chloroform. After two weeks with intermittent shaking a slight yellow discolouration was seen suggestive of leaching of minor amounts of low molecular weight material but the bulk remained as a robust solid.

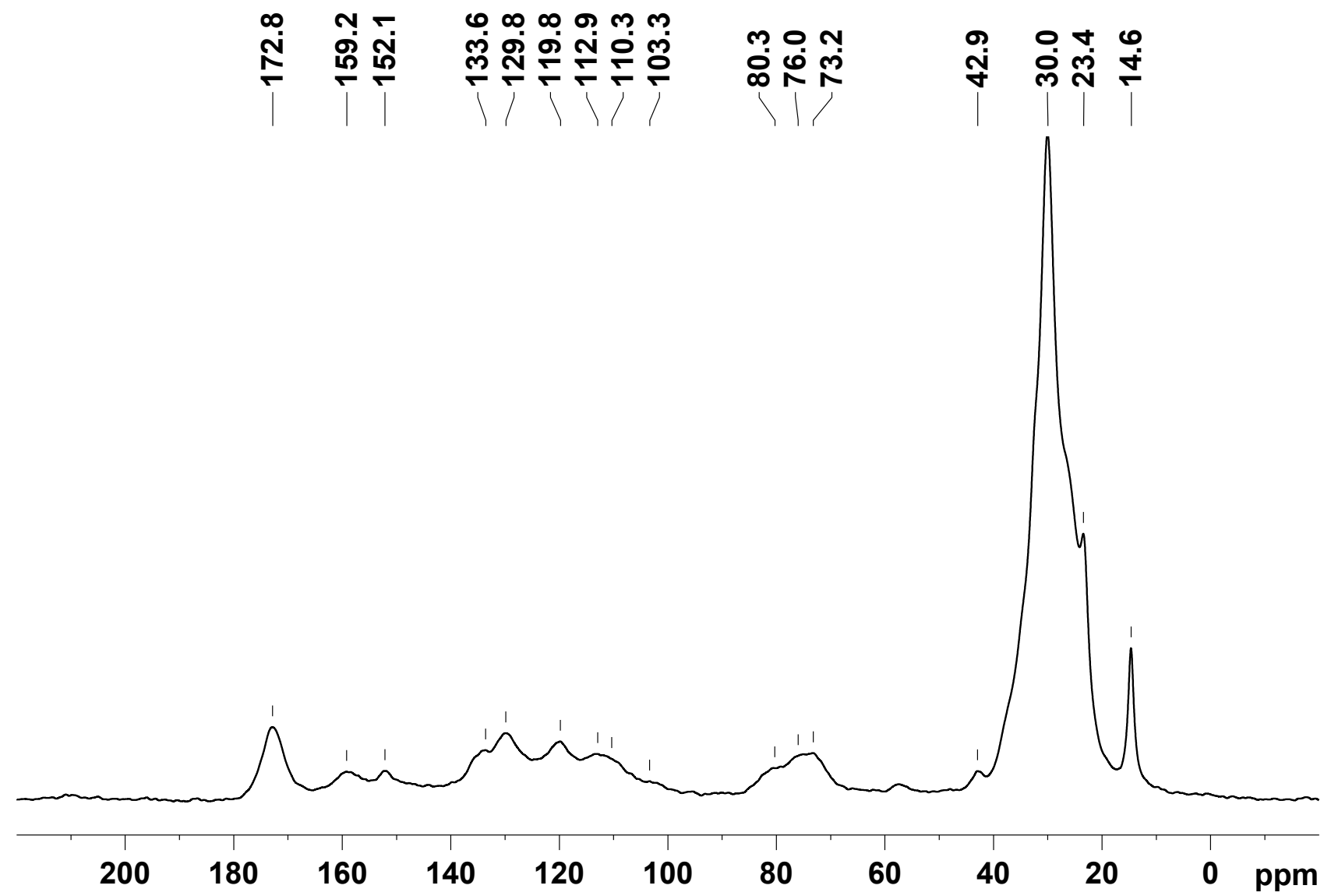

Figure 8. The solid state CPMAS TOSS ${ }^{13} \mathrm{C}$ NMR spectrum of epoxide D cured with PPD.

The solid-state ${ }^{13} \mathrm{C}$ NMR spectrum (Figure 8 ) shows only a small signal at 58 ppm, which can be attributed to either the residual oxirane carbon (expected at $54-57 \mathrm{ppm}^{15,60}$ ) or to the end group $>\mathrm{CH}-\mathrm{N}$ carbon. This confirms that the majority (if not all) of epoxy rings have been opened. As confirmed by ${ }^{13} \mathrm{C}$ CPMAS NQS TOSS spectra, aromatic C-N and C-O peaks are at 144-162 ppm 
and the ester remains intact with a carbonyl signal at $173 \mathrm{ppm}$. The aromatic $\mathrm{CH}$ carbons are at 102$136 \mathrm{ppm}$ and the aliphatic $>\mathrm{CH}-\mathrm{O}$ carbons are at $68-86 \mathrm{ppm}$. The remaining aliphatic methylene carbons are at 21-44 ppm and the methyl carbons are at $15 \mathrm{ppm}$.

The orcinol-diepoxide (epoxide $\mathbf{C}$ ) which had not been subjected to column purification was cured with PPD at $150{ }^{\circ} \mathrm{C}$ for 16 hours and produced a hard solid that was insoluble in chloroform after 2 weeks indicating that the purification step is not essential for creating a strong solid.

Similarly when column-purified epoxides B-E were subjected to high temperature curing with PPD by heating for 16 hours at $150{ }^{\circ} \mathrm{C}$, hard solids were formed. These conditions were effective in curing these epoxy resins whereas lower temperatures or heating times yielded samples that were incompletely solidified. All PPD-cured diepoxide resins produced insoluble black solids which were highly resistant to scratching or indentation. After initial curing, the samples were tested at $200{ }^{\circ} \mathrm{C}$ where no significant signs of melting or alteration of their characteristic features were observed suggesting they had formed thermosets. These observations imply that these samples had all formed extensively cured epoxy resins. Once the resins had cured they appeared strong and highly resistant to removal from the glass sample tube. These properties suggest that the polymers have the potential for applications as adhesives with high temperature resistance. Initially, the epoxy resins were highly transparent, colourless or pale yellow oils. On addition of PPD the mixtures turned orange-brown colour and became slightly cloudy becoming increasingly dark in colour as the reactions progressed. The final products were black and opaque.

PPD appears to be a highly effective hardener though unfortunately it does not occur naturally. Preliminary tests were carried out into the hardening efficacy of norspermidine as curing agent however these yielded viscous liquids as products. The molecular structure of DET is much shorter overall than norspermidine and PPD, which also cures well, is also shorter and more rigid than DET given its central aromatic ring. Possibly the terminal amine "heads" find it easier to crosslink two epoxy-monomers when the monomers are not required to be so widely spaced.

\section{Interactions with Smectite Clay}

The swelling of clays by polymer precursors indicates the possibility of preparing nanocomposites by intercalation followed by in situ curing and was assessed by change of the basal plane spacing $\left(\mathrm{d}_{001}\right)$ of pristine clay and four modified clays using XRD. Methanol was used as solvent to introduce organic species so a control trace is shown in Figure 9 for the effect of methanol alone. The (001) peak at $7.1^{\circ}(12.5 \AA)$ for the untreated clay is shifted slightly to $7.2^{\circ}$ (12.2 A) suggesting methanol removes some gallery water. The methanol-MMT trace therefore offers a control for all subsequent experiments: methanol being used as solvent in each case. 


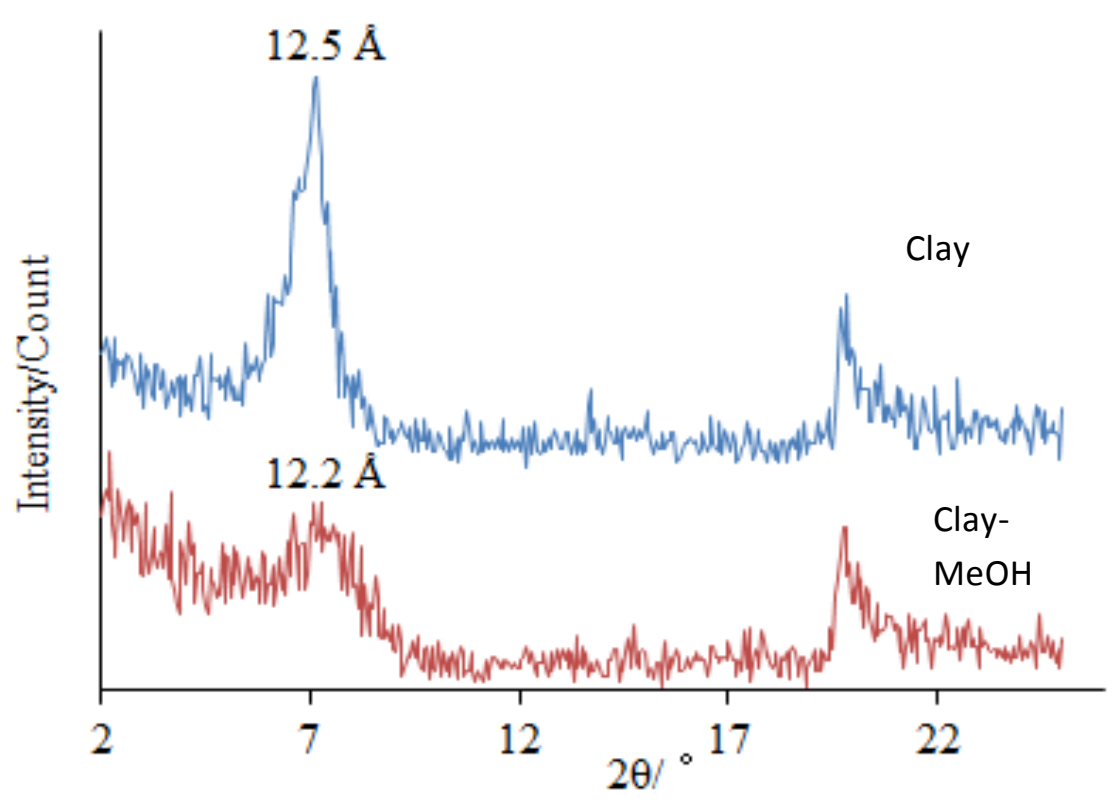

Figure 8. X-ray diffraction patterns of clay as-received and clay dispersed in methanol and then dried (Traces have been shifted on the ordinate for clarity).

Reagent oleic acid dissolved in methanol had no significant effect on $\mathrm{d}_{001}$ after $86 \mathrm{ks}$ (1 day), $2.6 \mathrm{Ms}$ (1 month), or $7.8 \mathrm{Ms}$ (3 months). Similarly, the epoxystearic acid produced a single peak at $12.5 \AA$ after 2.6 Ms (1 month) immersion (Figure 10). It appears that intercalation of these precursors does not provide a pathway to nanocomposite formation with untreated montmorillonite.

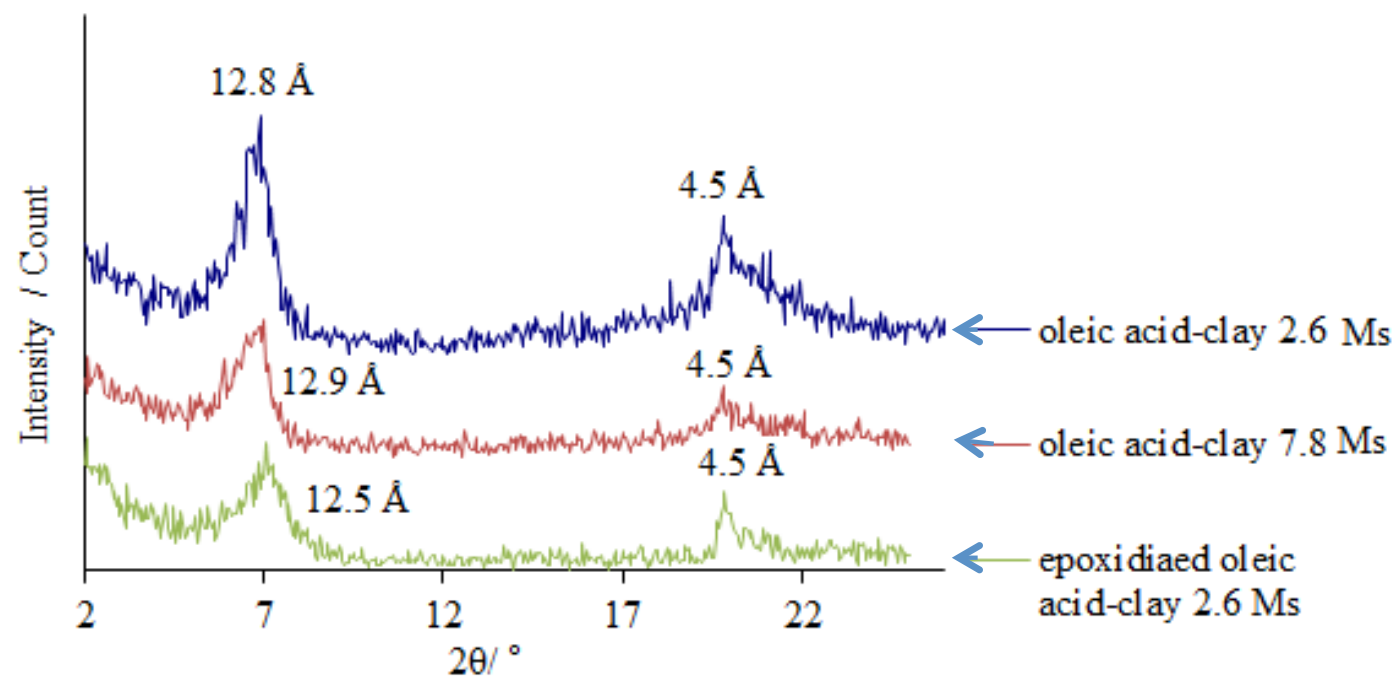


Figure 10. X-ray diffraction patterns of clay treated with oleic acid (1 month and 3 months) and epoxystearic acid ( 1 month) using methanol as solvent. (Traces have been shifted on the ordinate for clarity).

The XRD traces for the clays treated with epoxystearic oleic acid showed that for PPD modified clay, no intercalation occurred and $\mathrm{d}_{001}$ increased by only $0.2 \AA$. The $\mathrm{d}_{001}$ for ALA modified clay actually decreased by $1.5 \AA$, suggesting that methanol extraction of the aminolauric acid took place. The DET modified clay also did not accept the epoxystearic acid.

Figure 11 shows XRD patterns of the commercially available Cloisite ${ }^{\circledR} 10 \mathrm{~A}$ with oleic acid. This organophilic clay which is treated with a benzyl(hydrogenated tallow alkyl)dimethyl salt giving it an initially higher basal spacing is generally regarded as a receptive host for polymers ${ }^{44}$. Oleic acid increased $\mathrm{d}_{001}$ from $19.2 \AA$ to $23.2 \AA$, an expansion of $21 \%$ and a new peak appeared at $15.8 \AA$.

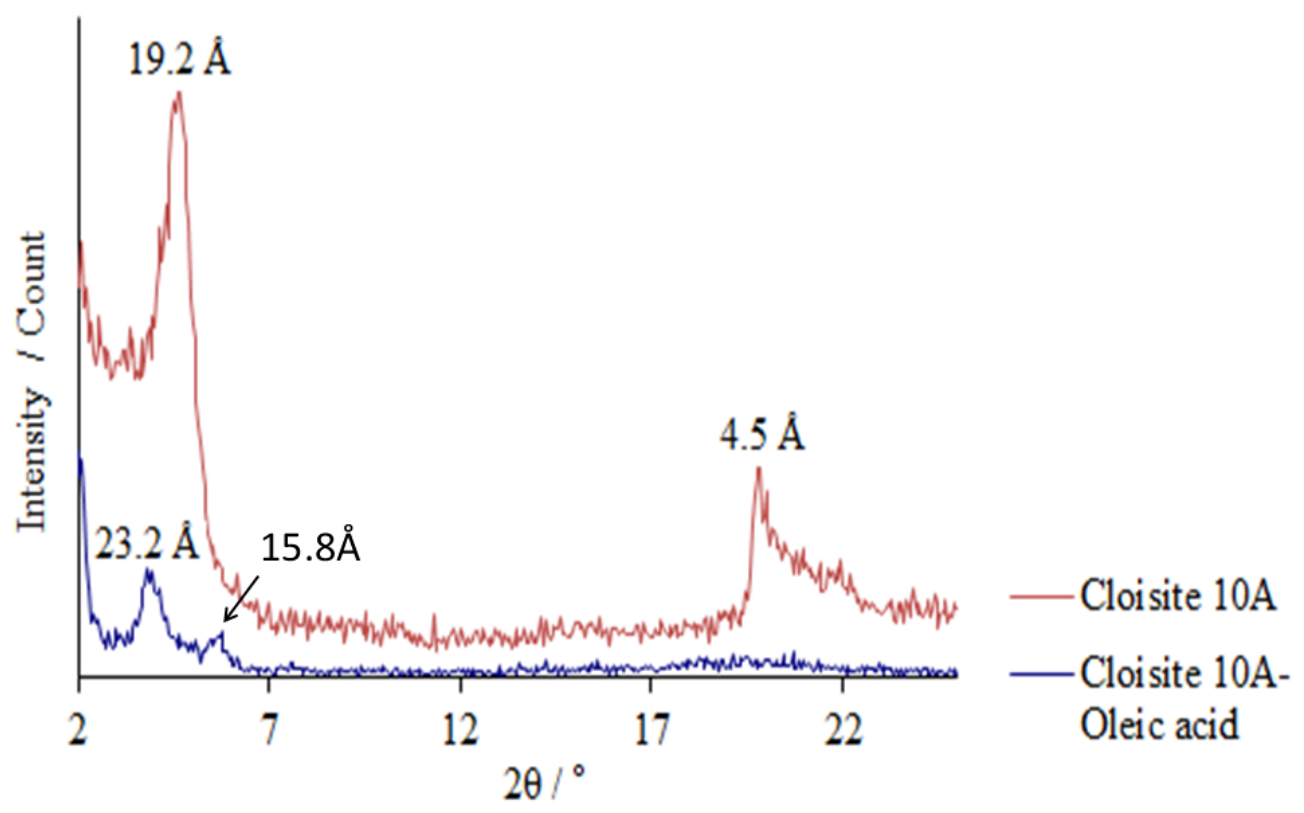

Figure 11. X-ray diffraction patterns of organoclay with oleic acid using methanol as solvent. (Traces have been shifted on the ordinate for clarity).

The use of untreated clay is preferred for an industrial procedure since no additional step is needed and the cost of feedstock is lower but these advantages must be set against the mechanical and barrier properties of the resulting composite. This work indicates that the polymer precursors do not intercalate from solution in untreated clay and even in clay that has been pretreated to make it compatible with epoxy resins. The commercial clay Cloisite $10 \mathrm{~A}$ with an initially much expanded basal plane does host oleic acid in the galleries and provides a direction to epoxy-clay nanocomposites with low petroleum input. In support of this conjecture, an epoxidized soybean oil 
has been shown to produce intercalated nanocomposites with $5 \mathrm{wt} . \%$ of a comparable organoclay that offers 3.5 times modulus and twice the tensile strength without loss of elongation at break. ${ }^{61}$

\section{Conclusions}

This work sets out several alternatives to the homopoplymerization of epoxystearic acid so that oleic acid from seed waste can be incorporated into materials manufacture. Oleic acid was esterified with propanediol, orcinol and resorcinol to provide a precursor with two double bonds which were then epoxidized using hydrogen peroxide or meta-chloroperbenzoic acid. Similarly a dioleamide was prepared with norspermidine and epxoidized. These precursors were cured at $150{ }^{\circ} \mathrm{C}$ using diethylenetriamine or p-phenylenediamine to produce hard insoluble resins. Furthermore, the products of epoxystearic acid and anhydride obtained at $165{ }^{\circ} \mathrm{C}$ which were not crosslinked could then be esterified using resorcinol or orcinol so that esterification became the last step. While neither oleic acid nor epoxystearic acid intercalated into unmodified montmorillonite, an organoclay was found that acted as a host for oleic acid and this opens the possibility for in situ intercalation so that a new family of epoxy nanocomposites could be prepared with considerably reduced petroleum input.

\section{Acknowledgments}

The authors are grateful to John Hill for the mass spectrometry and to Illya Litvinov for synthesis of treated clays.

\section{References}

1 C. K. Williams, M. A. Hillmyer, Polym. Revs. 48, 2008, 1-10.

2 IBIB.2012-13. 2012. International Business Directory for Innovative Bio-Based Plastics and Composites Nova-Institute GmbH Huerth, Ger. \& Bioplastics Magazine

3 H. J. Endres, A. Siebert-Raths, 2011. Engineering Biopolymers: Market, Manufacturing, Properties and Applications, Hanser Publications.

4 C. Michael, T. Michael, 2012. International Business Directory for Innovative Bio-Based Plastics and Composites, Nova-Institute $\mathrm{GmbH}$, Bioplastics Magazine.

5 J-M. Raquez, M. Deléglise, M-F. Lacrampe, P. Krawczak, Prog. Polym. Sci. 2010, 35, 487-509.

6 A. Rouilly, L. Rigal, J. Macromol. Sci. C: Polymer Reviews, 2002, C42, 441-479.

7 X. Tong, Y. Ma, Y. Li, Appl. Catal. A- General, 2010, 385, 1-13.

8 C. K. Williams, M. A. Hillmyer, Polymers from Renewable Resources, Polymer Reviews, 2008, 48: 1-10 
9 R. T. Mathers, How Well Can Renewable Resources Mimic Commodity Monomers and Polymers? J. Polym. Sci. A: Polym. Chem. 2012, 50, 1-15

10 J. B. S. F. Filho, M. Horridge, Land Use Policy 36, (2014), 595-604.

11 B. Eickhout, H. V. Meijl, T. V. Rheenen, Land Use Policy 24, (2007), 562-575.

12 S. A. Sanchez-Vazquez, H.C. Hailes, J. R. G. Evans, Polym. Revs., 2013, 53, 627-694.

13 M. A. R. Meier, J. O. Metzger, U. S. Schubert, Chem. Sci. Revs. 36, (2007), 1788-1802.

14 F. S. Guner, Y. Yaget, A. T. Erciyes, Prog Polym. Sci. 31, (2006), 633-670.

15 A. Nicolau, R. M. Mariath, E. A. Martini, D. S. Martini, D. Samios, Mater. Sci. Eng. C 30, (2010), 951962.

14 C. A. May, Epoxy Resins: Chemistry and Technology, 2nd Edn., 1988 Marcel Dekker, Inc. NY 10016, pp. $1-3$.

17 N. Galego, A. Vazquez, R. J. J. Williams, Polymer, 1994, 35, 857-861.

18 W. F. Schroeder, S. V. Asmussen, M. Sangermano, C. I. Vallo, Polymer Int., 2013, 62, 1368-1376.

19 RAPRA Technology Ltd. (1996) Recent Developments in Epoxy Resins.: RAPRA Review Reports, Report 91, RAPRA, Shrewsbury, UK pp. 25-28.

20 P. Mohan, P., Polym.-Plast. Technol. Eng., 2013, 52, 107-125.

21 P. Roumanet, F. Lafleche, N. Jarroux, Y. Raoul, S. Claude, P. Guegan, Euro. Polym. J., 2013, 49, 813822.

22 V. V. Goud, S. Dinda, A. V. Patwardhan, N. C. Pradhan, Asia-Pacific J. Chem. Eng., 2010, 5, 346-354.

23 R. A. Fong, S. N. Lewis, R. J. Wiersema, A. G. Zielske, Glycolate ester peracid precursors, U.S. Patent No. 4,778,618. 18 Oct. 1988.

24 G. Chávez, R. Hatti-Kaul, R. A. Sheldon, G. Mamo, J. Molecular Catal B: Enzymatic 89, (2012), 67-72.

25 J. Zuo, S. Li, L. Bouzidi, S. S. Narine, Polymer, 2011, 52, 4503-4516.

26 World of Chemicals, 2013, Orcinol [online], WOC Labs Pte. Limited, Singapore, available from: http://www.worldofchemicals.com/chemicals/chemical-properties/orcinol.html [accessed 20 Mar 2014].

27 Net Industries Online Encyclopedia, 2014, Resorcin [online], available from:

http://encyclopedia.jrank.org/RAY_RHU/RESORCIN_meta_dioxybenzene_C5H4.html [accessed $20 \mathrm{Mar}$ 2014].

28 R. R. Mod, F.C. Magne, G. Sumrell, J. Amer. Oil Chem. Soc., 1971, 48, 254-256.

29 eCompound, 2007, Common reaction procedures [online], available from:

http://www.ecompound.com/Reaction\%20reference/Lab\%20rat\%20procedures.htm [accessed 03 Dec 2013].

30 G. Astarita, B. Di Giacomo, S. Gaetani, F. Oveisi, T. R. Compton, S. Rivara, G. Tarzia, M. Mor, D.

Piomelli, J. Pharmacol. Experim. Therapeutics, 2006, 318, 563-570.

31 B. Rodriguez-Garay, G. C. Philips, G. D. Kuehn, Plant physiol., 1989, 89, 525-529.

32 K. Hamana, S. Matsuzaki, J. Biochem., 1982, 91, 1321-1328.

33 S. Yamamoto, S. Shinoda, M. Makita, Biochem. Biophys. Res. Commun., 1979, 87, 1102-1108.

34 H. Dannenberg, W. R.Harp, Anal. Chem., 1956, 28, 86-90. 
35 X. Pan, P. Sengupta, D. C. Webster, Biomacromolecules 2011, 12, 2416-2428.

36 X. Pan, D. C. Webster, Macromol. Rapid Commun. 2011, 32, 1324-1330.

37 G. Tillet, B. Boutevin, B. Ameduri., Prog. Polym. Sci. 36, (2011), 191-217.

38 T. M. Goulding, Epoxy resin adhesives, Handbook of Adhesive Technology (1994), 531.

39 J. Luston, F. Vass, Adv. Polym. Sci. 56, (1984), 91-133.

40 H. Lee, K. Neville, Handbook of Epoxy Resins, McGraw-Hill Book Company, New York, 1967, pp. 5.25.13.

41 K. J. Saunders, Organic Polymer Chemistry, Chapman and Hall, London, 1988, pp. 424-427.

42 R. M. Wik, Henry Ford and Grass-roots America; Univ. Michigan Press: Ann Arbor, MI, 1992; pp 148152.

43 A. Okada, A. Usuki, Macromol. Mater. Eng. 291 (2006) 1449-1476.

44 B. Chen, J. R. G. Evans, H. C. Greenwell, P. Boulet, P. V. Coveney, A. A. Bowden, A. Whiting, Chem. Soc. Revs. 37, (2007), 568-594.

45 E. Mularczyk, J. Drzymala, Separation Sci. Technol. 24, (1989), 151-155.

46 G. Haraldsson, J. Amer. Oil Chem. Soc. 61, (1984), 219-222.

47 L. Maisonneuve, T. Lebarbe, T. H. N. Nguyen, E. Cloutet, B. Gadenne, C. Alfos, H. Cramail, Polym. Chem., 2012, 3, 2583-2595.

48 R. G. Bistline, W. M. Linfield, W. B. Wise, P. E. Pfeffer, P. E. Sonnet, E. G. Piotrowski, J. Amer. Oil Chem. Soc., 1987. 64, 744-748.

49 B. R. Moser, S. Z. Erhan, Eur. J. Lipid, Sci. Technol., 2007, 109, 206-213.

50 D. Swern, G. N. Billen, J. T. Scanlan, J. Amer. Chem. Soc., 1948, 70, 1226-1228.

51 J. Rosch, R. Mulhaupt, Polym. Bull. 31, (1993), 679-685.

52 J. Ma, Y. Pang, M. Wang, J. Xu, H. Ma, X. Nie, J. Mater. Chem. 22, (2012), 3457-3461.

53 A. Akelah, P. Kelly, S. Qutubuddin, A. Moet, Clay Minerals, 29 (1994):169-178.

54 M. Sangermano, G. Malucelli, G. Delleani, A. Priola, Polym. Int., 2007, 56, 1224-1229.

$55 \mathrm{~J}$. Coates, Interpretation of infrared spectra, a practical approach, Encyclopedia of analytical chemistry (2000), 10815-10837.

56 D. E. James, J. K. Stille, J. Org. Chem. 41, (1976), 1504-1511.

57 F. Busque, P. de March, M. Figueredo, J. Font, Tetrahedron, 51, (1995), 1503-1508.

58 J. V. Paukstelis, E. F. Byrne, J. Org. Chem. 42, (1977), 3941-3944.

59 B. S. Buyuktas, Transit. Metal Chem. 31, (2006), 786-791.

60 N. D. Sachinvala, D. L. Winsor, R. K. Menescal, I. Ganjian, W. P. Niemczura, M. H. Litt, J.Polym. Sci. A Polym. Chem 36, (1998), 2397-2413.

61 V. Tanrattanakul, P. Saithai, J. Appl. Polym. Sci. 114, (2009),3057-3067. 
